ARTICLE

https://doi.org/10.1038/s41467-019-12968-y

\title{
Epithelial CD47 is critical for mucosal repair in the murine intestine in vivo
}

Michelle Reed ${ }^{1,2}$, Anny-Claude Luissint (10 1,2, Veronica Azcutia (10 1, Shuling Fan', Monique N. O'Leary', Miguel Quiros ${ }^{1}$, Jennifer Brazil ${ }^{1}$, Asma Nusrat ${ }^{1} \&$ Charles A. Parkos (ib ${ }^{1 *}$

CD47 is a ubiquitously expressed transmembrane glycoprotein that regulates inflammatory responses and tissue repair. Here, we show that normal mice treated with anti-CD47 antibodies, and Cd47-null mice have impaired intestinal mucosal wound healing. Furthermore, intestinal epithelial cell (IEC)-specific loss of CD47 does not induce spontaneous immunemediated intestinal barrier disruption but results in defective mucosal repair after biopsyinduced colonic wounding or Dextran Sulfate Sodium (DSS)-induced mucosal damage. In vitro analyses using primary cultures of CD47-deficient murine colonic IEC or human colonoid-derived IEC treated with CD47-blocking antibodies demonstrate impaired epithelial cell migration in wound healing assays. Defective wound repair after CD47 loss is linked to decreased epithelial $\beta 1$ integrin and focal adhesion signaling, as well as reduced thrombospondin-1 and TGF- $\beta 1$. These results demonstrate a critical role for IEC-expressed CD47 in regulating mucosal repair and raise important considerations for possible alterations in wound healing secondary to therapeutic targeting of CD47.

\footnotetext{
${ }^{1}$ Department of Pathology, University of Michigan, Ann Arbor, MI 48109, USA. ${ }^{2}$ These authors contributed equally: Michelle Reed, Anny-Claude Luissint. *email: cparkos@med.umich.edu
} 
C D47 is a ubiquitously expressed cell surface glycoprotein that associates with a variety of receptors to facilitate critical cell signaling events. Of considerable interest, CD47 has been implicated to regulate innate immune cell tolerance of self through its ability to ligate signal-regulatory protein alpha/SIRPa on myeloid immune cells and inhibit phagocytosis of circulating CD47-expressing erythrocytes ${ }^{1-6}$. This mechanism is currently being exploited in studies on CD47 as a potential target for immunotherapeutics intending to augment immunemediated destruction of cancer cells that overexpress $\mathrm{CD} 47^{7,8}$.The altered susceptibility of $C d 47$-deficient mice to inflammatory insults further suggest that CD47 expression is an important modulator of leukocyte function during pro-inflammatory immune responses ${ }^{9-14}$. However, a lack of tissue-targeted knockout mice has limited studies that address the function of CD47 expression by non-hematopoietic cell types in vivo.

It is well appreciated that adhesion and collective migration of epithelial cells is particularly important during mucosal wound closure, as restoration of the epithelial barrier is necessary for the resolution of inflammation ${ }^{15}$. Studies suggest that collective migration of epithelial cell monolayers across denuded surfaces requires dynamic regulation of $\beta 1$ integrin signaling, which directs the rapid formation and dissolution of focal adhesions ${ }^{16-18}$. In vitro studies using cell lines suggest that CD47 is also an important regulator of integrin signaling through in cis interactions with integrin heterodimers. Specifically, it has been reported that CD47 expression regulates integrin-dependent cell adhesion and migration in smooth muscle cells, platelets, and epithelial cells in vitro ${ }^{19-22}$, as well as enabling integrin-mediated leukocyte adhesion and extravasation in vivo ${ }^{23}$. However, the potential regulation of epithelial $\beta 1$ integrin signaling by CD47 during mucosal wound closure in vivo has not been investigated. Noteworthy, CD47 has been reported to play a role in tissue repair with improved healing and survival in several in vivo models including skin thermal injury and ischemia/reperfusion in organ transplant models of liver, kidney, and skin ${ }^{24-29}$. Given these observations, we surmised that expression of CD47 in epithelial cells may play an important role in regulating mucosal wound closure in vivo. Studies were performed to evaluate the role of epithelial CD47 expression in models of intestinal mucosal injury and repair in vivo. Here, we report that $C d 47$-deficient mice and wild-type animals infused with CD47-neutralizing antibodies have markedly impaired biopsy-induced colonic wound closure. We further demonstrate a critical role of epithelial expressed CD47, as mice selectively deficient in intestinal epithelial cell (IEC) CD47 expression did not display abnormalities under resting conditions but exhibited profound defects in closure of biopsy-induced mucosal wounds as well as markedly impaired colonic mucosal wound repair from cyclic exposure to dextran sodium sulfate (DSS)-induced injury. Using two-dimensional (2D) cultures of primary epithelial cells derived from murine and human intestine, it was determined that CD47 regulates epithelial cell migration and wound closure through $\beta 1$ integrin-dependent signaling through Focal adhesion kinase (FAK), Src protein-tyrosine kinase, and Crk-associated substrate p130Cas (p130Cas), thereby controlling the formation of focal cell matrix adhesions. In addition, we observed that loss of CD47 negatively regulates the level of expression of its ligand thrombospondin-1 (TSP-1) and effector cytokine Transforming growth factor beta (TGF- $\beta 1$ ) both known to facilitate wound healing ${ }^{30-32}$, resulting in alteration of downstream signaling pathways. Herein, we corroborate evidence of crosstalk between CD47, $\beta 1$ integrin, and focal adhesions as well as a functional link between CD47, TSP-1, and TGF- $\beta 1$ in the intestinal epithelium. These findings provide insights into a central role of CD47 in regulating IEC migration and mucosal wound repair in vivo, and raise the possibility of altered wound healing as a potential complication in clinical studies exploring blockade of CD47 to enhance clearance of CD47-overexpressing tumor cells in humans.

\section{Results}

CD47 expression is required for mucosal repair in vivo. Previous studies with total $C d 47$ knockout mice $\left(C d 47^{-/-}\right)$have shown varied results in response to inflammatory challenge, including a protective effect of CD47 deficiency during ischemia/ reperfusion injury and total body irradiation ${ }^{13,28}$, as well as in response to certain pathogens ${ }^{33}$. However, CD47 deficiency has also been reported to increase susceptibility to systemic Escherichia coli and Candida albicans infection ${ }^{10,11}$. As mucosal wound repair in the intestine requires coordinated epithelial migration and proliferation in concert with temporal immune responses ${ }^{15}$, we hypothesized that CD47 may have an important role in regulation of wound healing. To test this hypothesis, we utilized a mucosal repair model employing miniaturized endoscopic biopsy-based mechanical injury and video analysis of recovery in the colonic mucosa of $C d 47^{-1-}$ mice. To analyze repair, sizes of mucosal wounds were digitally quantified 1 day after initial wounding and compared with sizes of the same wounds 2 days later. $C d 47^{-1-}$ mice showed markedly inhibited wound closure compared with wild-type controls (Fig. 1a).

Although the above results suggest that loss of CD47 impairs mucosal wound closure, recent studies employing systemic blockade of CD47 with monoclonal antibodies suggest beneficial effects in some murine models of inflammation ${ }^{34,35}$. We therefore tested whether systemic or local administration of CD47-blocking antibodies had inhibitory effects on mucosal wound healing. Indeed, intraperitoneal injection of the CD47-blocking antibodies miap301 or miap410 significantly inhibited wound closure in C57Bl/6 mice (Fig. 1c). As systemic blockade of CD47 would be expected to alter immune cell extravasation ${ }^{23}$, we locally injected CD47-blocking antibodies directly into colonic wound beds $24 \mathrm{~h}$ post wounding and assessed wound closure. Similar results to those observed with systemic antibody administration as well as in Cd47 knockout mice were obtained (Fig. 1b, c), suggesting that both localized and systemic neutralization of CD47 significantly delay mucosal wound healing.

Loss of epithelial CD47 impairs wound healing responses. As CD47 is ubiquitously expressed, understanding contributions of specific CD47-expressing cell types in mucosal wound-healing responses is critical to gain detailed mechanistic insights. Unfortunately, in vivo studies on CD47 function have been hindered by a lack of tissue-targeted, selectively deficient $C d 47$ knockout mice. Given that mucosal wound healing is dependent on coordinated migration and proliferation of the intestinal epithelium, and CD47 is implicated in cell adhesion and migration in vitro ${ }^{19}$, we created mice with selective loss of CD47 in the intestinal epithelium by generating $C d 47$ floxed mice $\left(C d 47^{\mathrm{f} / \mathrm{f}}\right)$, which were bred to mice constitutively expressing Cre under control of the Villin promoter $\left(C d 47^{\Delta \mathrm{IEC}}\right)$. Specific CD47 loss in IECs of $C d 47^{\Delta I E C}$ mice was confirmed by immunofluorescence labeling and western blotting (Fig. 2a, b).

As CD47 expression is described as an innate marker of self ${ }^{4}$, we anticipated that spontaneous immune-mediated destruction of the intestinal epithelium might develop in Cre-expressing mice. $C d 47^{\Delta I E C}$ mice weighed the same as littermate controls (Supplementary Fig. 1a) and exhibited no signs of spontaneous intestinal inflammation or epithelial barrier dysfunction. Furthermore, $C d 47^{\Delta \mathrm{IEC}}$ mice did not show evidence of increased intestinal permeability to $4 \mathrm{kD}$ dextran (Supplementary Fig. 1b) consistent with normal barrier function. Histological examination 
a
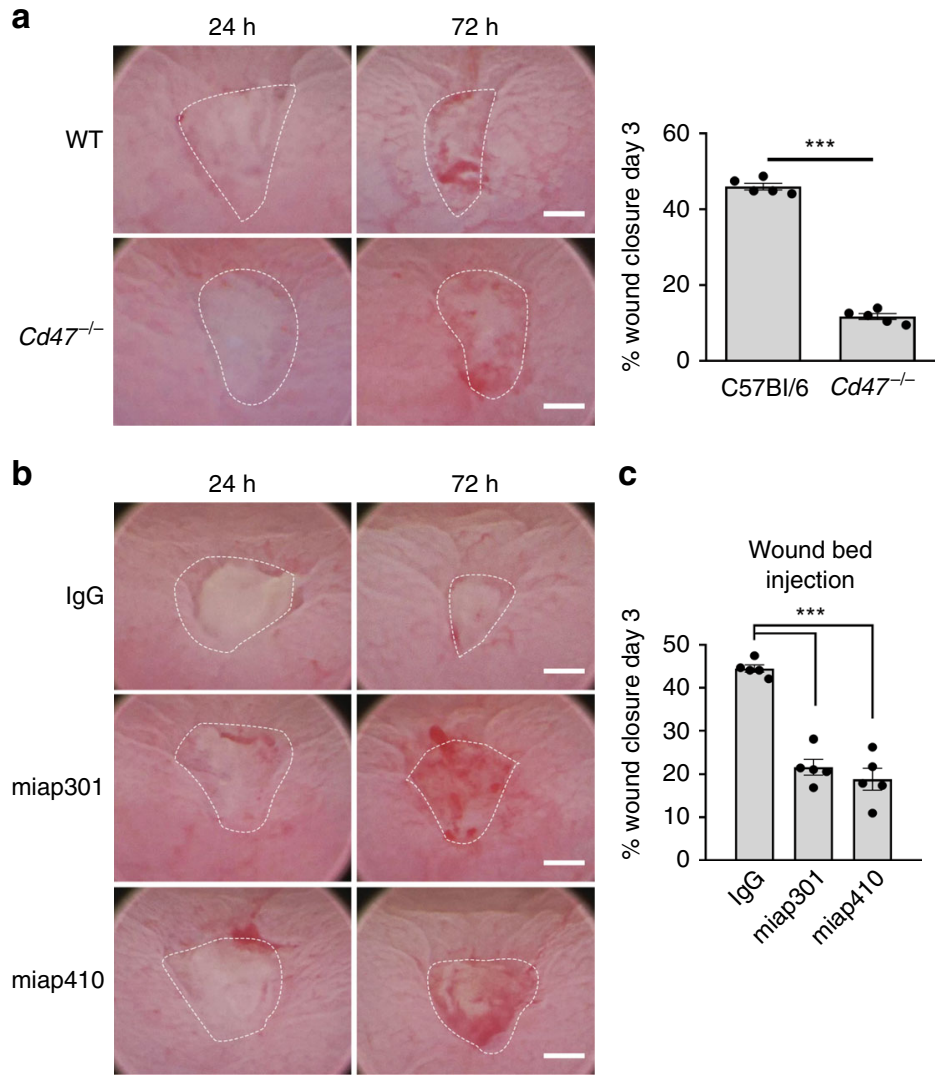

C
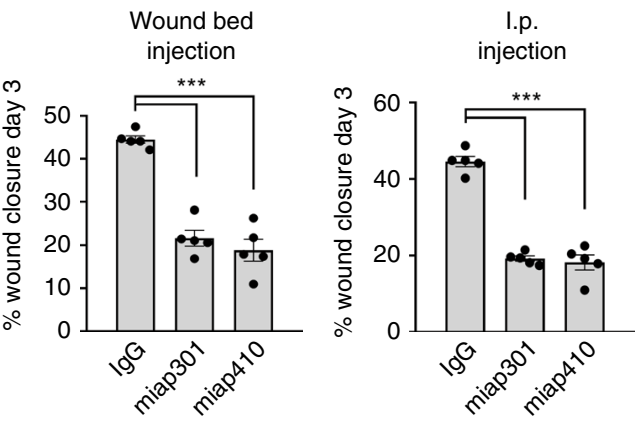

Fig. 1 CD47 regulates mucosal wound healing in vivo. Utilizing a miniature video endoscope and biopsy scissors, 5-7 wounds were created in the dorsal aspect of the descending colon mucosa of anesthetized mice. a Digital measurement of wound surface area at 24 and $72 \mathrm{~h}$ post wounding revealed a striking impairment in wound closure in $C d 47^{-/}$mice. Points represent the mean value within all wounds from individual mice. Data are representative of three independent experiments with five mice per group and are expressed as means \pm SEM. ${ }^{\star \star \star} p<0.001$; two-tailed Student's $t$ test. $\mathbf{b}$ In total, $10 \mu g$ of control antibody (IgG) or anti-CD47 antibody (miap301 or miap410) were injected into wound beds of wounds created $24 \mathrm{~h}$ previously in C57BI/6 mice, resulting in substantial reduction of wound closure upon blockade of CD47. c Mice treated locally or systemically with anti-CD47 monoclonal antibodies miap301 or miap410 experienced less wound area reduction in comparison with lgG-treated controls. Points represent mean value within all wounds from an individual mouse. Data are representative of two independent experiments with five mice per group. Date are means \pm SEM. ${ }^{\star \star \star} p<0.001$; one-way ANOVA. Scale bars: $50 \mathrm{~mm}$. Source data are provided as a Source Data file

of intestinal mucosa revealed normal architecture in $C d 47^{\Delta \text { IEC }}$ mice (Fig. 2d), and no significant inflammation or alterations in major tissue-resident immune cell populations assessed by flow cytometry (Fig. 2e). To verify that the lack of observed spontaneous inflammation in $C d 47^{\Delta I E C}$ mice is not owing to immune compensation during development ${ }^{5}, C d 47^{\mathrm{f} / \mathrm{f}}$ mice were also bred to animals expressing an ERT2-Cre fusion protein under control of the Villin promoter ${ }^{36}$ to obtain mice with inducible loss of CD47 in the intestinal epithelium ( $\left.C d 47^{\mathrm{ER}} \mathrm{IIEC}\right)$. Tamoxifen treatment of $C d 47^{\mathrm{ER} \Delta \mathrm{IEC}}$ mice resulted in acute deletion of CD47 in IECs, which persisted 60 days post tamoxifen treatment (Fig. 2a, c). In agreement with results obtained from naive $C d 47^{\Delta \mathrm{IEC}}$ mice, $C d 47^{\mathrm{ER} \Delta \mathrm{IEC}}$ mice showed no signs of altered intestinal epithelial barrier function or pathologic mucosal inflammation, as evidenced by analysis of body weight, mucosal histology/immune cell populations, and barrier function (Supplementary Fig. 1c-e).

Having established that IEC-targeted Cd47-deficient mice do not develop significant intestinal pathology under baseline conditions, we tested whether epithelial CD47 expression is required for mucosal wound healing. Consistent with our findings in $C d 47^{-1-}$ mice and wild-type mice treated with anti-CD47 antibodies, $C d 47^{\Delta \mathrm{IEC}}$ mice as well as tamoxifen-treated $C d 47^{\mathrm{ER} \Delta \mathrm{IEC}}$ mice showed profound impairment in biopsy-induced wound closure between 1 and 3 days post wounding in comparison with littermate controls (Fig. 3a). Thin cross-sections of wound beds labeled with the epithelial-specific marker E-Cadherin and brush border protein Villin revealed the absence of polarized woundassociated epithelial cells expressing Villin in $C d 47^{\Delta I E C}$ mice compared with control $C d 47^{\mathrm{f} / \mathrm{f}}$ mice (Fig. 3b, c). In addition, examination of proliferation of cells in crypts adjacent to mucosal wounds isolated from $C d 47^{\Delta \mathrm{IEC}}$ and tamoxifen-treated $C d 47^{\mathrm{ER} \Delta \mathrm{IEC}}$ mice revealed similar numbers of Ki67-labeled epithelial cells (Fig. 3d), indicating similar levels of epithelial cell proliferation regardless of CD47 expression. Collectively, these findings indicate that epithelial CD47 promotes colonic mucosal wound healing by regulating IEC migration but not cell proliferation.

In order to verify the observed, wound healing defects in $C d 47^{\Delta \mathrm{IEC}}$ and tamoxifen-treated $C d 47^{\mathrm{ER} \Delta \mathrm{IEC}}$ mice, we utilized a second model of chronic colonic mucosal injury and repair that employs cyclical administration of DSS in drinking water followed by recovery with water alone. When subjected to alternating cycles of DSS administration and water-only recovery, both $C d 47^{\Delta I E C}$ and tamoxifen-treated $C d 47^{\mathrm{ER} \triangle \mathrm{IEC}}$ mice developed escalating clinical colitis scores (Disease Activity Index (DAI)) as determined by weight loss, stool consistency, and presence of blood in stools, in comparison with littermate controls (Fig. 4a, b). Colitis/DAI was more pronounced following induced deletion of CD47 in tamoxifen-treated $C d 47^{\mathrm{ER} \Delta \mathrm{IEC}}$ mice (Fig. 4b). Histological analysis of the colonic mucosa after three 
a
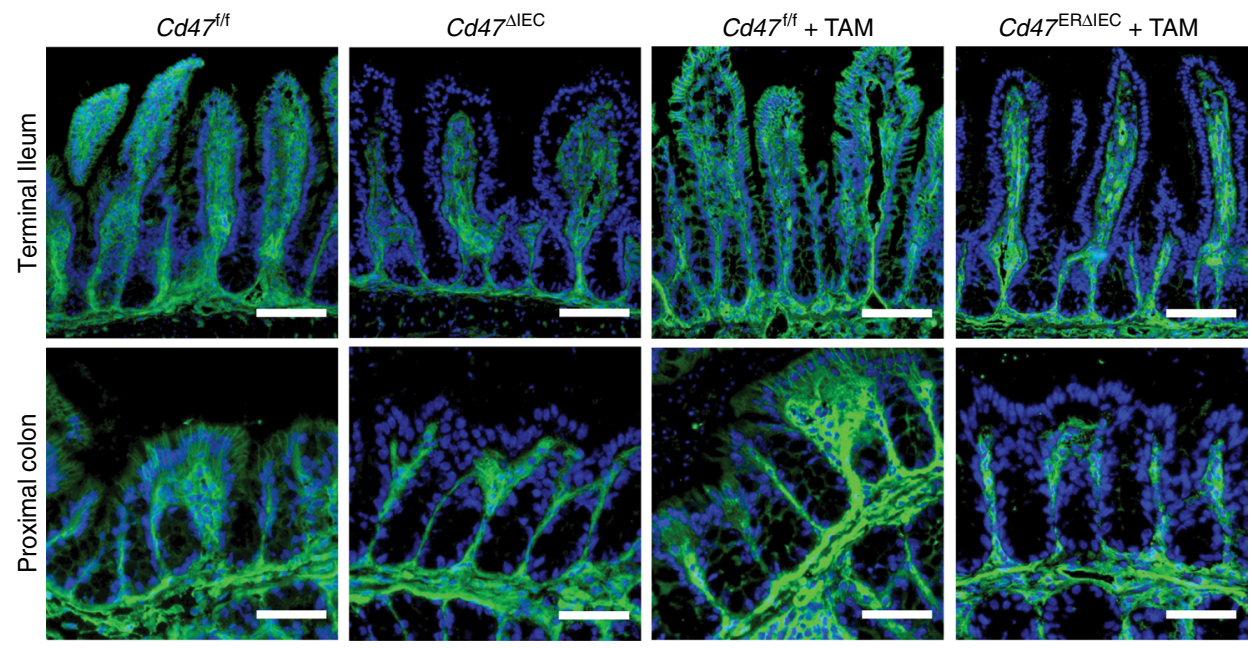

b

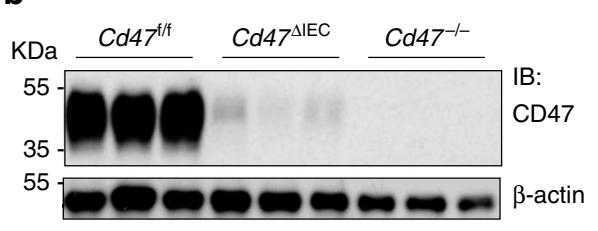

C

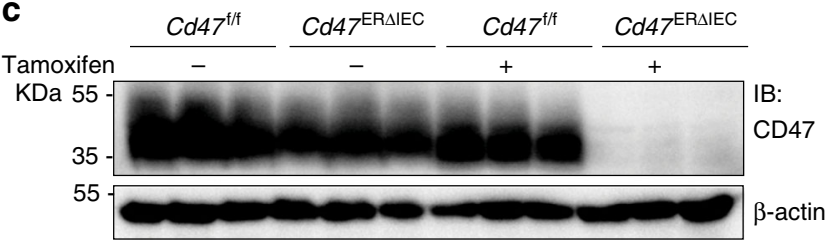

e
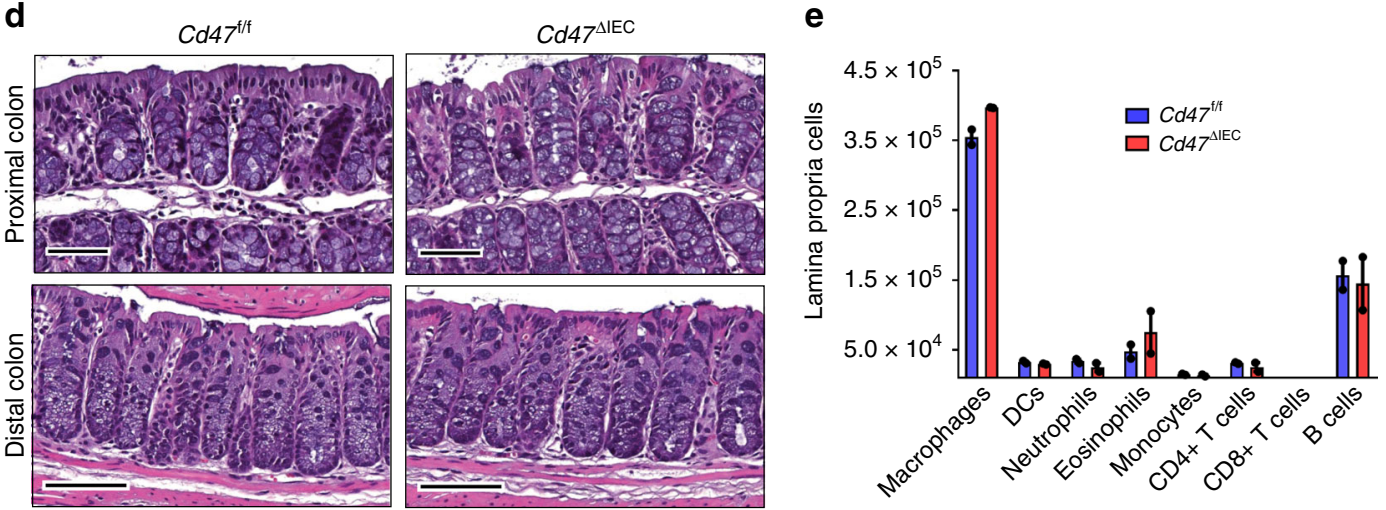

Fig. 2 Loss of CD47 in IEC does not induce immune-mediated mucosal damage. a-c Naive Cd47AIEC and tamoxifen-treated Cd47ERAIEC mice housed in pathogen-free conditions were analyzed for intestinal epithelial CD47 expression. Cd47ERAIEC mice were treated with tamoxifen to induce acute CD47 deletion in intestinal epithelial cells, and analyzed 2 weeks later. a Tissue sections from naive Cd47DIEC and tamoxifen-treated $C d 47 E R \Delta I E C$ mice were stained with anti-CD47 antibodies (green) with DAPI counterstain (blue). CD47 expression is absent in the epithelium but retained in the lamina propria and submucosa. Scale bars $=100 \mu \mathrm{m}$ upper panels, $50 \mu \mathrm{m}$ lower panels. $\mathbf{b}$ IECs were isolated from the terminal ileum of naive mice. Protein lysates were analyzed by SDS-PAGE and immunoblot for CD47. c IECs were isolated from Cd47ERAIEC mice treated with vehicle (corn oil) or tamoxifen, and analyzed as in $\mathbf{b}$. Results are representative of three independent experiments with 3-5 mice per group. $\mathbf{d}$ Paraffin-embedded colon tissue sections from $C d 47 \Delta \mathrm{EC}$ mice were stained with Hematoxylin and Eosin counterstain for histological examination. Gross mucosal architecture is intact in the absence of epithelial CD47 expression. Scale bars $=50 \mu \mathrm{m}$ upper panels, $100 \mu \mathrm{m}$ lower panels. e Colon tissue digests from naive $\mathrm{Cd} 4 \mathrm{~T}^{\Delta \mathrm{IEC}}$ mice were stained and analyzed by flow cytometry, showing no significant differences in major lamina propria immune cell populations. Points represent individual samples each containing two mice ( $n=4$ mice per group). Data are means \pm SEM and are representative of three independent experiments. Source data are provided as a Source Data file

cycles of DSS and water administration revealed significantly worse mucosal injury and less repair in $C d 47^{\Delta I E C}$ mice and tamoxifen-treated $C d 47^{\mathrm{ER}} \Delta \mathrm{IEC}$ mice, with increased crypt loss and mucosal ulceration evident in the distal colon (Fig. 4c-e). PMN/ granulocytes were visualized in the inflamed colonic mucosa of both genotypes with prominent accumulations of PMN observed in $C d 47^{\triangle \mathrm{IEC}}$ mice (Supplementary Fig. 2). These findings indicate that loss of CD47 results in impaired mucosal recovery associated with persistent inflammation in $C d 47^{\Delta \mathrm{IEC}}$ mice in response to chronic DSS. In contrast, acute DSS treatment without recovery period did not produce statistically significant disease differences between groups (Supplementary Fig. 3a, b), further supporting impaired mucosal healing responses in $C d 47^{\Delta I E C}$ and Cd47ER $\triangle$ IEC mice.

CD47 regulates focal adhesion-dependent IEC migration. To gain further insight into the molecular basis of delayed wound closure in epithelial cells lacking CD47, we analyzed wound closure in cultures of primary epithelial cells derived from either murine small intestinal enteroids or from human stem cellderived epithelial colonoids. Murine CD47-deficient enteroid 
a

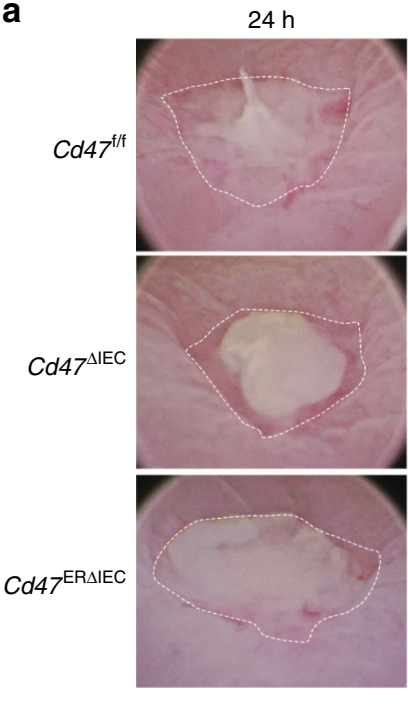

C
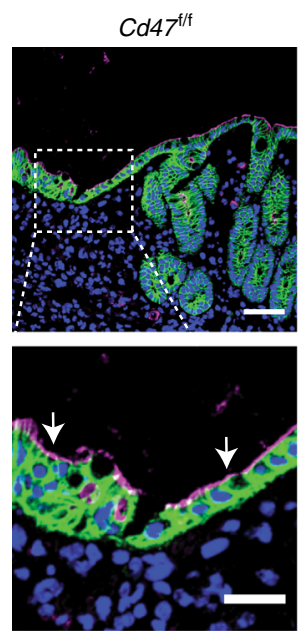

$72 \mathrm{~h}$

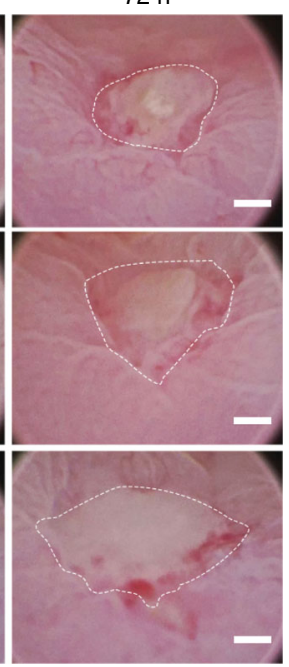

$C d 47^{\Delta I E C}$
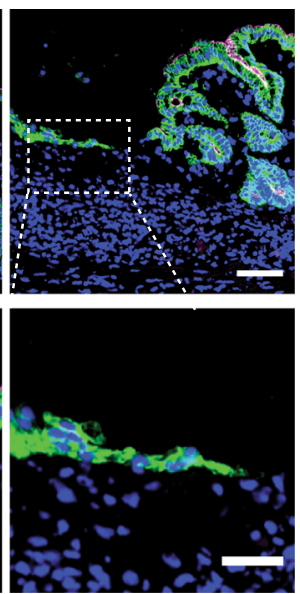

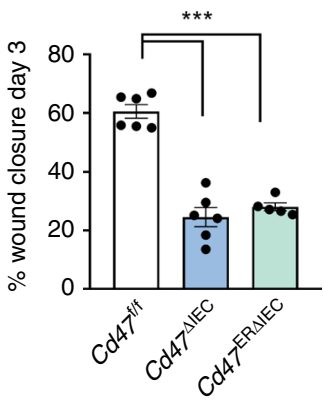

b
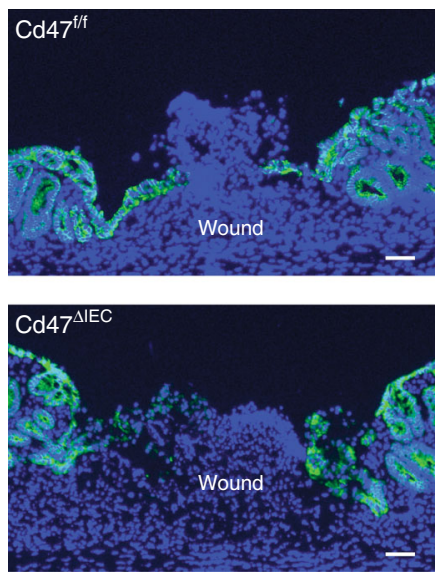

d
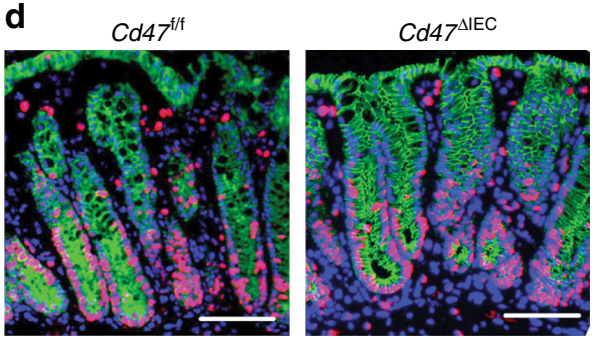

$C d 47^{\mathrm{ER} \Delta \mathrm{EEC}}$
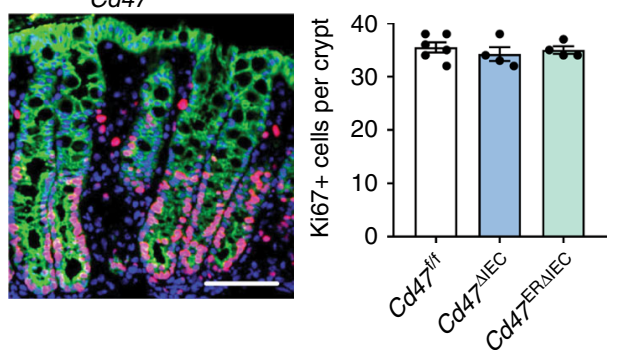

Fig. 3 IEC-specific deletion of CD47 results in impaired mucosal healing. Utilizing a miniature video endoscope and biopsy scissors, 5-7 wounds were created in the dorsal aspect of the descending colon mucosa of anesthetized mice. Cd47ERAIEC mice were wounded 2 weeks after tamoxifen treatment. a Digital measurement of wound surface area at 24 and $72 \mathrm{~h}$ post wounding revealed a striking impairment in wound closure in $C d 47^{\Delta I E C}$ and tamoxifentreated $C d 47 E R \Delta I E C$ mice. Points represent mean value within all wounds from an individual mouse. Data are representative of two independent experiments with 5-6 mice per group. Data are means \pm SEM. ${ }^{\star \star *} p<0.001$; one-way ANOVA. $\mathbf{b}$ Tissue sections taken from day 3 wounds were stained with the epithelial-specific marker E-Cadherin (green), plus DAPI counterstain (blue). Re-epithelialization of the wound is disorganized in the absence of

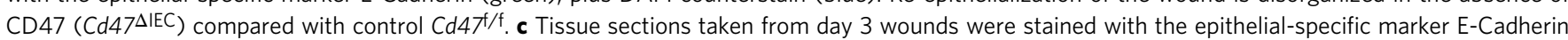
(green), brush border protein Villin (magenta), and DAPI (blue). Insets of epithelial cells on top of the wound bed show polarized wound-associated epithelial cells (WAE) expressing Villin (arrows) in Cd47/f wounds while cells are not polarized in Cd47 $4 \mathrm{IEC}$ wounds. Scale bars $=100 \mu \mathrm{m}$. $\mathbf{d}$ Ki67 staining of frozen sections of wounded colon mucosa 3 days post-wounding (red) revealed similar proliferation rates in crypt epithelial cells immediately adjacent to wounds in the absence of epithelial CD47. Sections were counterstained with E-Cadherin (green) and DAPI (blue). Scale bars $=50 \mu \mathrm{m}$. Points represent the average number of Ki67-positive cells for four crypts adjacent to wounds for each individual mouse. Data are means \pm SEM and are representative of two independent experiments with 4-6 mice per group. Source data are provided as a Source Data file

cultures were generated by treating Cd47ERAIEC intestinal enteroids with either vehicle (control) or $1 \mu \mathrm{M} 4$-hydroxytamoxifen (4$\mathrm{OHT}$ ) for $72 \mathrm{~h}$ to induce Cre-mediated recombination and stable CD47 knockdown $(\mathrm{CD} 47(+)$ or CD47(-), respectively). Deletion of CD47 in 4-OHT-treated enteroid cultures was verified by semiquantitative real-time PCR and western blotting (Supplementary Fig. 4a, b). Subsequently, 2D epithelial cell monolayers were generated from CD47 $(+)$ or CD47(-) enteroids and subjected to scratch-wound healing assays. Although epithelial proliferation rates were similar between $\operatorname{CD} 47(+)$ and $\operatorname{CD} 47(-)$ cultures (Supplementary Fig. 4c), time lapse imaging of scratch induced wounds revealed significantly delayed closure in monolayers lacking CD47 (Fig. 5a).

To further verify that blockade of CD47 impairs closure of wounds, we incubated human colonoid-derived epithelial monolayers with the well-characterized CD47-blocking antibody $\mathrm{B} 6 \mathrm{H} 12^{37}$. In comparison with IgG control, treatment with B6H12 significantly reduced wound closure, whereas incubation with the non-blocking anti-CD47 antibody 2D3 did not impede wound closure (Fig. 5b). Similar results were obtained by treating 
a

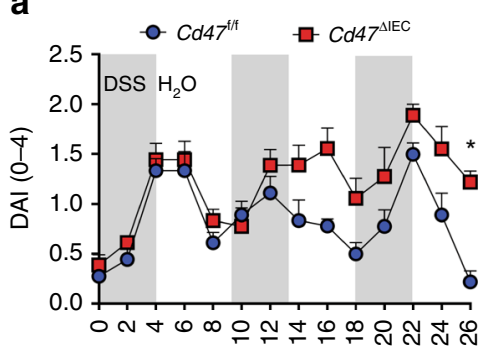

Day

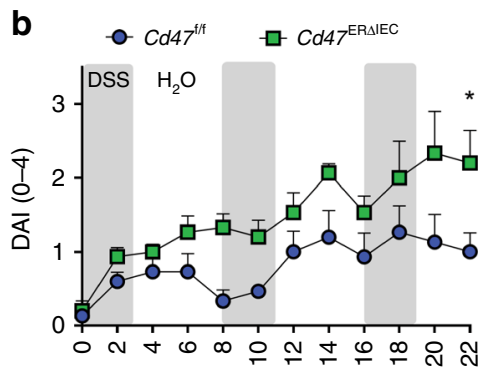

Day
C

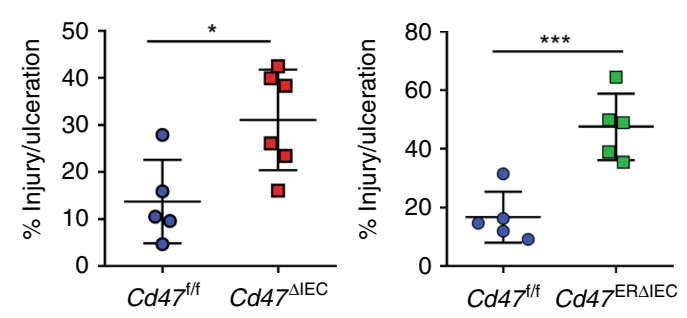

d

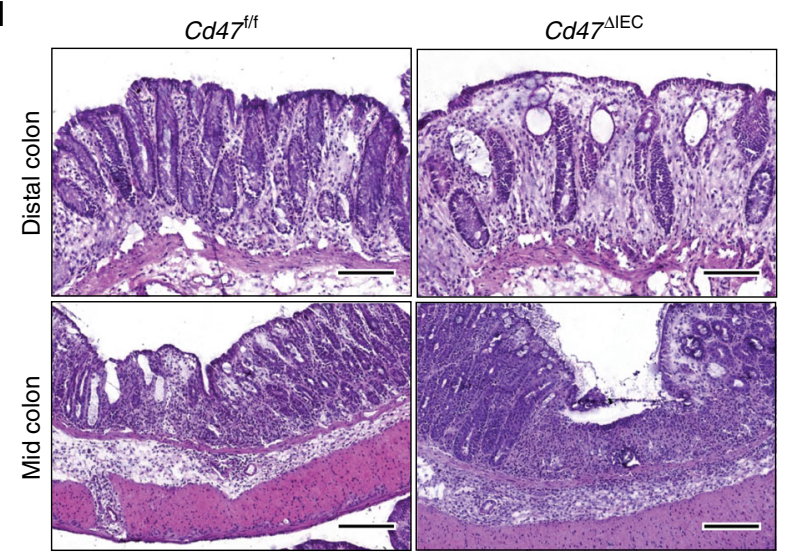

e

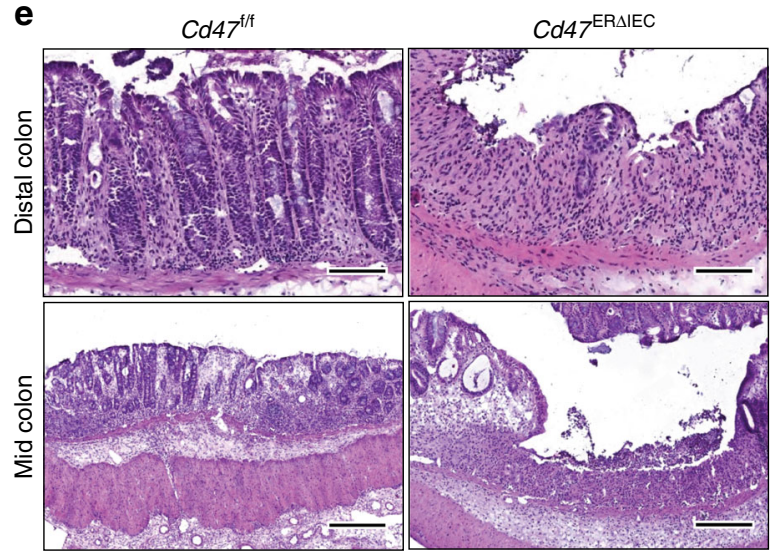

Fig. 4 Loss of CD47 in IEC results in impaired recovery from DSS-induced colitis. Age- and sex-matched Cd47AIEC and tamoxifen-treated Cd47FR $\Delta \mathrm{IEC}$ mice

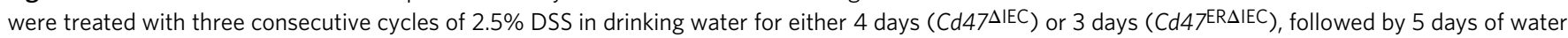
recovery. Cd47ERAIEC mice were treated with DSS 2 weeks after tamoxifen treatment. a-b Disease activity index scores are represented as an average of scores 0-4 for percent weight loss, stool consistency, and presence of blood in stools. Cyclical treatment of a Cd47 $\Delta \mathrm{IEC}$ and $\mathbf{b}$ tamoxifen-treated $C d 47^{E R \Delta I E C}$ mice with $2.5 \%$ DSS in drinking water, followed by a plain water recovery period, induced greater DAI scores in the absence of epithelial CD47. Data are representative of two independent experiments with 5-6 mice per group and are expressed as means \pm SEM. $\mathbf{a}{ }^{\star} p=0.02, \mathbf{b}{ }^{\star} p=0.036$ by twoway ANOVA. c Histological scoring of hematoxylin and eosin (H\&E)-stained tissue sections of colonic mucosa: percentage of injury/ulceration represents a ratio of the length of injured/ulcerated areas ( $\geq 50 \%$ crypt loss) relative to the entire colon length, as assessed in Swiss roll mounts of the entire colon. Results indicate greater damage in the absence of epithelial CD47. Points represent individual mice. Data are representative of two independent experiments with 5-6 mice per group and are expressed as means \pm SEM. Significance determined by two-tailed Student's $t$ test. ${ }^{\star} p=0.016,{ }^{\star \star \star} p=0.001$. d, e Representative H\&E staining of colon tissue sections after three cycles of DSS/water revealed extensive crypt destruction in distal colon of Cd47 $\triangle \mathrm{IEC}$

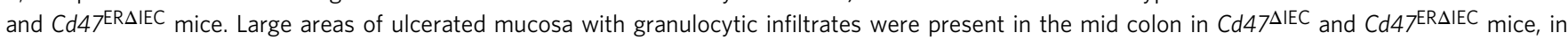
comparison with littermate controls. Scale bars $=100 \mu \mathrm{m}$ upper panels, $300 \mu \mathrm{m}$ lower panels. Results are representative of at least two independent experiments with 5-6 mice per group. Source data are provided as a Source Data file

CD47-expressing murine epithelial monolayers with the blocking anti-CD47 antibodies miap301 or miap410 (Supplementary Fig. 5), further supporting a functional requirement for CD47 in epithelial scratch-wound closure. Collectively, these in vitro results support the above in vivo findings (Fig. 3) suggesting that IEC-expressed CD47 does not regulate cell proliferation but acts to promote epithelial cell migration in response to wound injury.

Previous in vitro studies have suggested that CD47 has a role in regulation of integrin-dependent leukocyte adhesion through direct interaction with $\alpha \mathrm{V} \beta 3$ integrin in neutrophils and $\alpha 4 \beta 1 /$ $\alpha \mathrm{L} \beta 2$ integrins in $\mathrm{T}$ cells ${ }^{23,38}$. In epithelial cells, it is wellestablished that integrin alpha-beta heterodimers containing the $\beta 1$ subunit play a major role in epithelial cell migration through formation of focal adhesion complexes ${ }^{17,18}$, yet an interaction between CD47 and $\beta 1$ integrins has not been investigated in the intestinal epithelium. We utilized an in situ proximity ligation assay (PLA) to test whether CD47 closely interacts with $\beta 1$ integrin in murine colon. In Fig. 6a positive PLA signals were observed as green spots in IEC and immune cells with far fewer PLA signals observed in colonic crypts from $C d 47^{\Delta \mathrm{IEC}}$ mice (Fig. 6a). Importantly, in Supplementary Fig. 6, we demonstrated specificity of PLA staining in using $C d 47^{-/-}$and $C d 47^{+/+}$mice. As expected, no PLA signals were detected on IEC or immune cells in the colonic mucosa from $C d 47^{-1-}$ mice.

Previous studies have revealed that cell migration is dependent on temporal $\beta 1$ integrin-dependent focal adhesion complex formation in epithelial cells with recruitment and autophosophorylation of FAK at nascent adhesions, followed by the Src kinase-dependent phosphorylation of the adaptor protein p130Cas ${ }^{39-41}$. We assessed whether this signaling pathway is altered in the absence of epithelial CD47 expression. Indeed, freshly isolated IECs from $C d 47^{\Delta I E C}$ mice revealed reduced $\beta 1$ integrin protein expression in comparison with $C d 47^{\mathrm{f} / \mathrm{f}}$ controls, reduced Src phosphorylation at residue Y416 and FAK tyrosine phosphorylation at residues Y397 and Y861 $\left(\mathrm{pFAK}^{\mathrm{Y} 397}, \mathrm{pFAK}^{\mathrm{Y} 861}\right)$ as well as phosphorylation of p130Cas ${ }^{4} 10$ without change in total levels of Src and FAK (Fig. 6b). Similar results were obtained in wounded 2D epithelial cultures derived from murine enteroids, where CD47(-) monolayers had reduced $\beta 1$ integrin protein, $\mathrm{p}-\mathrm{Src}^{\mathrm{Y} 416}$, pFAK $^{\mathrm{Y} 397}, \mathrm{pFAK}^{\mathrm{Y} 861}$, and p130Cas ${ }^{\mathrm{Y} 40}$ after wounding (Fig. 6c). Reduction of $\beta 1$ integrin protein expression and altered $\mathrm{pFAK}^{\mathrm{Y} 861}$ in the absence of epithelial CD47 in vivo was 

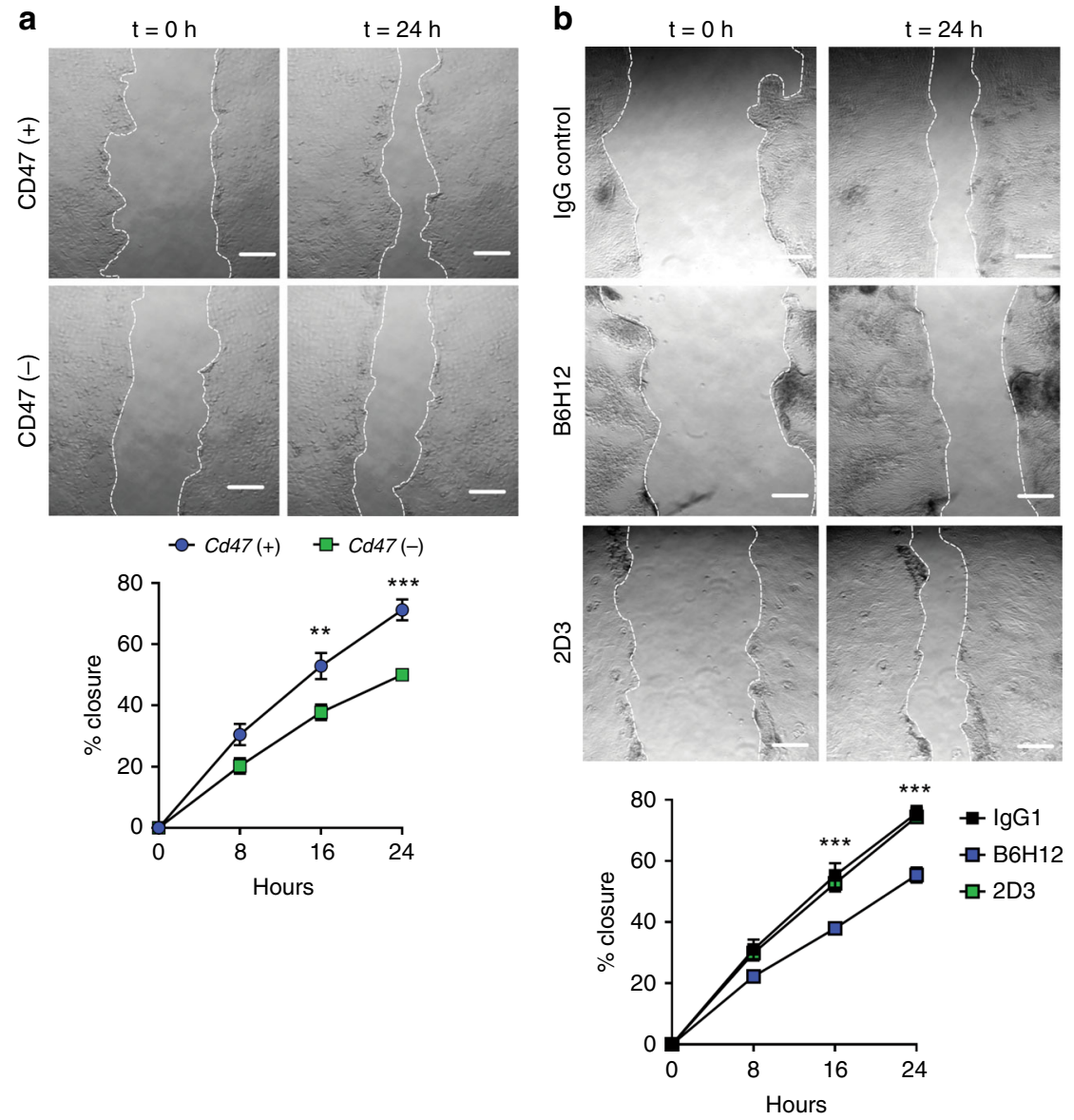

Fig. 5 CD47 is required for wound repair in cultures of primary epithelial monolayers. a Primary epithelial cell monolayers derived from CD47-expressing $(C D 47(+))$ or CD47-deficient (CD47(-)) murine enteroids were scratch-wounded and monitored for closure. CD47(-) epithelial monolayers showed significant impairment in reduction of scratch-wound surface area at $24 \mathrm{~h}$ post scratch. Edges of scratch wounds are indicated by dashed lines. Scale bars $=50 \mu \mathrm{m}$. b Primary epithelial cell monolayers derived from human stem cell-derived colonoids were scratch-wounded and treated with $10 \mu \mathrm{g} / \mathrm{ml}$ of either IgG control antibody, function-blocking anti-CD47 antibody (clone B6H12), or non-blocking anti-CD47 antibody (clone 2D3), resulting in the inhibition of cell migration upon blockade of CD47. a-b Results are representative of three independent experiments with three replicates per treatment group. Data are means \pm SEM. Significance determined by two-way ANOVA, ${ }^{\star \star} p \leq 0.01,{ }^{\star \star \star} p \leq 0.001$. Source data are provided as a Source Data file

confirmed through immunofluorescence staining and imaging of epithelium adjacent to healing wounds. Epithelial cells from $C d 47^{\triangle I E C}$ mice showed reduced basal staining for $\beta 1$ integrin and pFAK $^{\mathrm{Y} 861}$ and reduced colocalization of remaining $\beta 1$ integrin and $\mathrm{pFAK}^{\mathrm{Y} 861}$ at the base of the epithelium (Fig. $6 \mathrm{~d}$ ). As $\beta 1$ integrin-dependent signaling through FAK and p130Cas is necessary to direct formation and stabilization of adhesions in lamellipodia of migrating epithelial cells ${ }^{16,40}$, we analyzed focal adhesions in CD47(-) murine enteroid-derived epithelial cells. Immunofluorescence labeling of epithelial cells at the edges of healing wounds revealed typical focal adhesions in lamellipodia of leading-edge cells, visible as linear parallel $\mathrm{pFAK}^{\mathrm{Y} 861}$-staining structures connecting to the actin cytoskeleton in $\operatorname{CD} 47(+)$ cells. In contrast, very few $\mathrm{pFAK}^{\mathrm{Y} 861}$-staining focal adhesions were evident in lamellipodia of migrating CD47(-) (Fig. 6e). Similar results were obtained with $\mathrm{pFAK}^{\mathrm{Y} 397}$-staining lamellipodia of migrating $\mathrm{CD} 47(-)$ cells that was irregular and punctate in comparison with $\operatorname{CD} 47(+)$ cells (Supplementary Fig. 7). In combination with observations of altered signaling downstream of $\beta 1$ integrin in CD47-deficient cells, these results are consistent with a model of CD47-dependent regulation of $\beta 1$ integrin function and integrin-dependent regulation of focal cell matrix adhesion proteins, which control epithelial cell motility and thus contribute to wound closure.
CD47 regulates levels of TSP-1 and active TGF- $\beta$. The CD47 soluble protein ligand TSP-1 has been reported to facilitate tissue repair, as Tsp1-null animals has been shown to have delayed dermal wound healing and enhanced susceptibility to DSScolitis $^{30,42}$. We thus investigated whether loss of CD47 had an impact on TSP-1 expression in IEC. As shown in Fig. 7a, reduced expression of TSP-1 was detected in IEC freshly isolated from $C d 47^{\triangle I E C}$ mice in comparison with IEC from $C d 47^{\mathrm{f} / \mathrm{f}}$ mice at baseline. As TSP-1 has been reported to be an activator of latent TGF- $\beta 1$ to facilitate wound healing, re-epithelization and collagen synthesis $^{32,43}$, we examined the effect of CD47 loss on activation of TGF- $\beta 1$ and its downstream effectors as well as collagen deposition in colonic mucosa after injury. Freshly isolated IEC that lack CD47 expression had decreased expression of the mature cleaved form of TGF- $\beta 1$ and accumulation of the immature propeptide (Fig. 7a). Total expression levels and phosphorylation of Smad 2 and Smad3 were reduced similarly in IEC from $C d 47^{\Delta I E C}$ mice in comparison with $C d 47^{\mathrm{f} / \mathrm{f}}$ controls (Fig. 7a). Consistent with these findings, we observed less collagen staining in $C d 47^{\Delta \mathrm{IEC}}$ mice compared with $C d 47^{f / f}$ controls after chronic DSS-induced colitis or biopsy-based wounds at day 3 (Fig. 7b). Collectively, these data strongly suggest that in addition to controlling focal adhesion activity, CD47 also promotes intestinal wound healing through effects on epithelial levels of TSP-1 and TGF- $\beta 1$. 
a

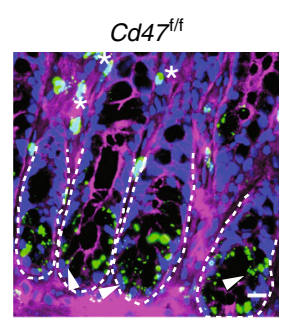

$C d 47^{\Delta \mathrm{IEC}}$

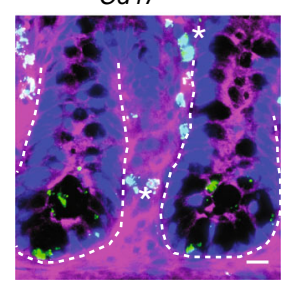

b

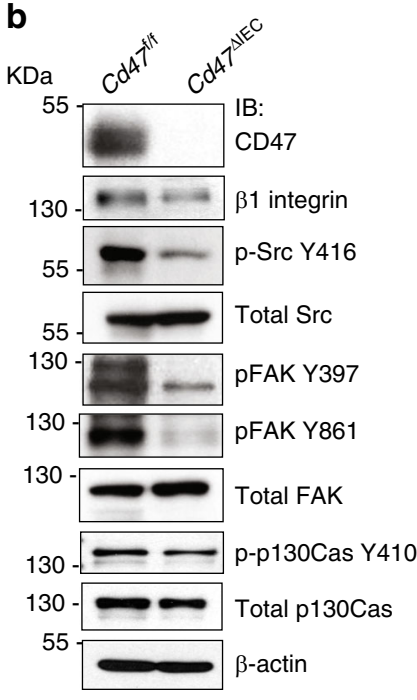

C

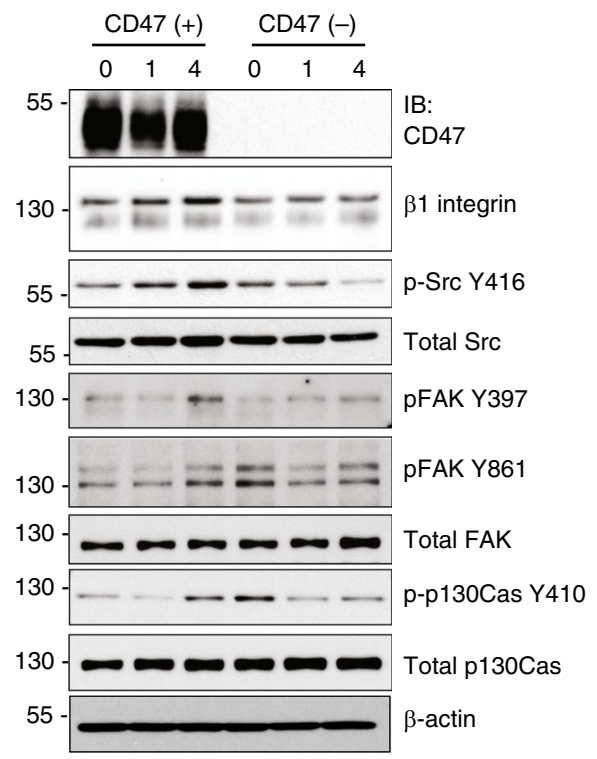

d
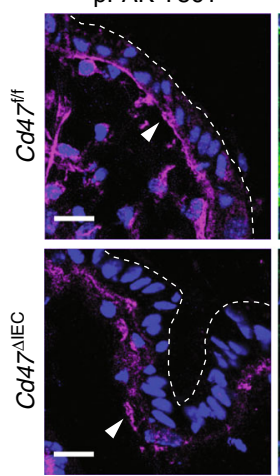

$\beta 1$ integrin

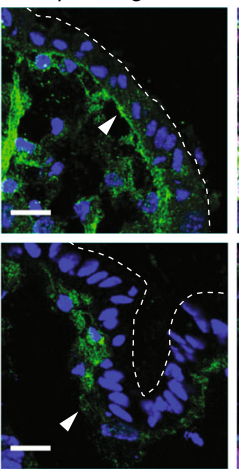

Merge

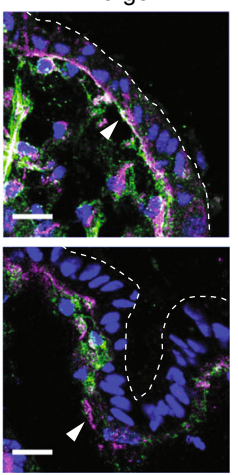

e

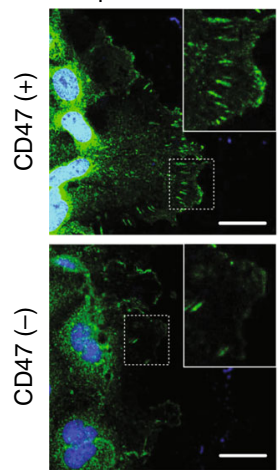

+ phalloidin

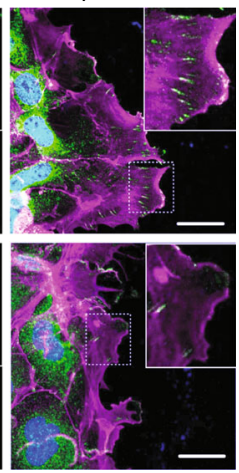

Fig. 6 CD47 associates with $\beta 1$ integrin and promotes focal adhesion formation. a In situ proximity ligation assay utilizing antibodies against CD47 and $\beta 1$ integrin indicating close association between CD47 and $\beta 1$ integrin in the colonic epithelium. Positive PLA signals are shown in green, beta-catenin in magenta and DAPI/nuclei in blue. Crypts are indicated by dashed lines. Arrowheads and asterisks $\left(^{*}\right)$ indicate positive PLA signals on IECs and immune cells in the lamina propria, respectively. Strong PLA signals are detected in IECs that are mainly concentrated at the base of the crypts in Cd47//f colon in contrast to very few PLA signals are observed in crypts IECs in Cd47 $\triangle \mathrm{IEC}$ colons. Scale bars $=20 \mu \mathrm{m}$. The specificity of the PLA signals was evaluated in Supplementary figure 6 demonstrating no PLA signals in $C d 47^{-/-}$colons. b Whole-cell lysates from freshly isolated intestinal epithelial cells from $C d 47^{f / f}$ and $C d 47 \triangle \mathrm{IEC}$ mice were subjected to SDS-PAGE and immunoblot for signaling molecules downstream of $\beta 1$ integrin-dependent cell adhesion, revealing decreased $\beta 1$ integrin protein expression and reduced phosphorylation of Src ${ }^{Y 416}$, FAK ${ }^{Y 397 / Y 861}$, and p130CAS ${ }^{Y 410}$ in cells from Cd47 $1 \mathrm{ECC}$ mice. Results are representative of three independent experiments. c Murine enteroid-derived primary epithelial cell monolayers were scratch-wounded and harvested at the indicated time points, then analyzed by SDS-PAGE and immunoblot. CD47-deficient epithelial cells show a reduction in phosphorylated Src ${ }^{Y 416}$, FAK ${ }^{Y 397 /}$ $Y 861$, and p130CAS $\mathrm{Y}^{410}$ upon wounding, whereas maintaining reduced $\beta 1$ integrin protein baseline expression. $\mathbf{d}$ Epithelial cells immediately adjacent to wounds from $C d 47^{f / f}$ and $C d 47^{\Delta I E C}$ mice were imaged by confocal microscopy, showing disrupted basal co-staining for phosphorylated FAK ${ }^{Y 861}$ and $\beta 1$ integrin (apical surface indicated by dashed line). Arrows indicate reduced colocalization of phospho-FAK ${ }^{\mathrm{Y} 861}$ and $\beta 1$ integrin in the absence of CD47 expression. Scale bars $=10 \mu \mathrm{m}$. Results are representative of three independent experiments with three mice per treatment group. e Lamellipodia of CD47 $(-)$ cells exhibited fewer phosphorylated FAK ${ }^{\mathrm{Y} 861}$-positive focal adhesions in comparison with CD47-expressing cells (insets). Scale bars $=10 \mu \mathrm{m}$. Results are representative of three independent experiments with two independently derived enteroid culture lines. Source data are provided as a Source Data file

\section{Discussion}

Despite the ubiquitous expression of CD47, very little is known about its function in non-hematopoietic cells. Previous studies employing models of inflammation in Cd47- null mice $\left(C d 47^{-1-}\right)^{9-11,13,14}$ or mice treated with CD47-neutralizing antibodies $^{34,35}$ support both protective and pathological roles for CD47 expression, yet are highly model-dependent and limited in their ability to distinguish between the relative contributions of CD47-deficient cell types in vivo. Here, we provide in vivo mechanistic insights into the functions of CD47 on IEC during homeostasis and in response to chemically or mechanically induced wounds. We have established that CD47 expression is required for normal mucosal wound healing, as $C d 47^{-1-}$ mice exhibited impaired colonic wound repair, an effect that was recapitulated in wild-type mice treated with CD47-neutralizing antibodies. It is possible that the observed wound healing defect in mice treated with anti-CD47 antibodies may, in part, be secondary to altered leukocyte responses, as CD47 has been reported to modulate leukocyte trans-endothelial migration ${ }^{23,34}$, cytokine production ${ }^{44-46}$, and bacterial killing ${ }^{10}$. Indeed, future studies utilizing cell type specific deletion of CD47 will be required to explore in depth the function of CD47 expression in other cell types during mucosal wound healing. However, here we show that epithelial CD47 expression is specifically required 
a

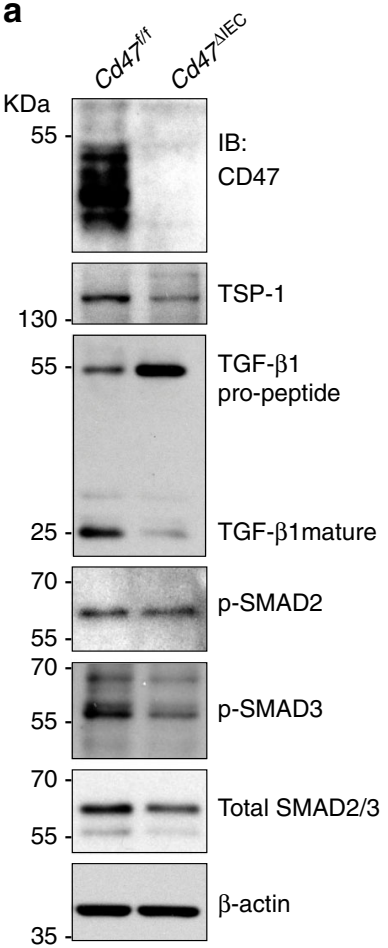

b
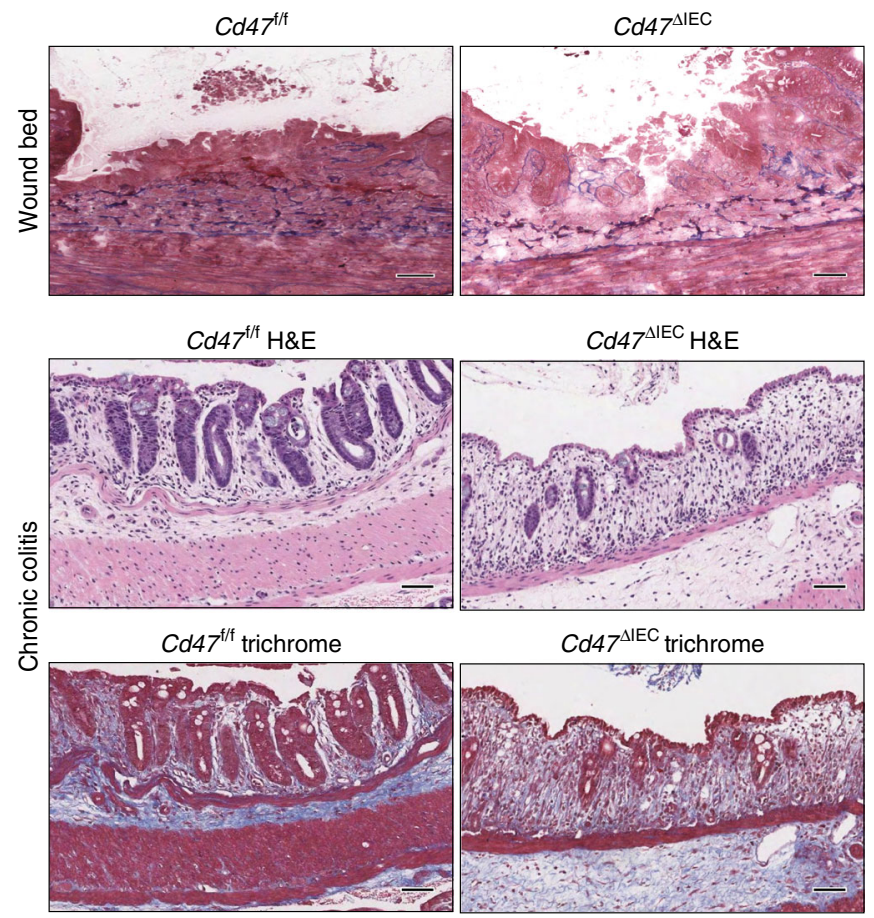

Fig. 7 CD47 regulates thrombospondin-1, TGF- $\beta 1$, and collagen deposition after injury. a Whole cell lysates from freshly isolated intestinal epithelial cells from $C d 47^{f / f}$ and $C d 47^{\Delta I E C}$ mice were subjected to SDS-PAGE and immunoblot for thrombospondin-1/TSP-1, TGF- $\beta 1$, and phosphorylated SMAD2 and SMAD3. Results are representative of three independent experiments. b Representative Masson's trichrome staining of wounds beds and chronic DSScolitis colons from $C d 47^{f / f}$ and $C d 47^{\Delta I E C}$ mice. Scale bars $=50 \mu \mathrm{m}$. Results representative of three independent experiments with 5-7 mice per group. Source data are provided as a Source Data file

for mucosal wound healing, as $C d 47^{\Delta \mathrm{IEC}}$ and tamoxifen-treated $C d 47^{\mathrm{ER} \Delta \mathrm{IEC}}$ mice exhibited profound impairment of mucosal biopsy wound closure and develop escalating mucosal damage after cyclical DSS treatment and recovery. Similar to a previous report that used $C d 47$-null mice ${ }^{47}$, we observed no direct consequences of loss of CD47 on IEC in response to acute DSS treatment in $C d 47^{\Delta \mathrm{IEC}}$ or $C d 47^{\mathrm{ER} \Delta \mathrm{IEC}}$ mice in comparison with controls. The same study also reported that Cd47-null mice are protected against prolonged administration of DSS to model chronic colitis owing to attenuated granulopoiesis leading to reduced PMN accumulation in colonic mucosa. Herein, our findings indicate that loss of CD47 on IEC rendered mice more susceptible to DSS-induced chronic colitis. Although we used a different DSS protocol for chronic colitis that mimics relapsing-remitting course of inflammatory bowel disease ${ }^{48,49}$, a major difference with the previous study by Bian et al. ${ }^{47}$ is that we used animals with selective deletion of CD47 on IEC rather than total body knockouts. Given that all other tissues including immune cells express CD47, one would not expect to observe alterations in granulopoeisis as well as primary defects in the capacity of granulocytes to be recruited into the intestinal mucosa after biopsy or DSS treatment. Indeed, PMN/granulocytes were detected in the inflamed mucosa of all genotypes $C d 47^{\triangle \mathrm{IEC}}, C d 47^{\mathrm{ER} \triangle \mathrm{IEC}}$, and control $C d 47^{\mathrm{f} / \mathrm{f}}$ mice after the last cycle of chronic DSS-induced colitis. We observed prominent infiltrates of PMN/granulocytes and large areas of crypt ulceration in $C d 47^{\Delta \mathrm{IEC}}$ and $C d 47^{\mathrm{ER}} \Delta \mathrm{IEC}$ mice, consistent with extensive epithelial damage and persistent inflammatory responses.

Studies employing transfer of CD47-deficient hematopoietic cells into wild-type hosts have informed the hypothesis that CD47 expression serves as an important marker of self, protecting CD47-expressing cells against errant destruction by phagocytic immune cells ${ }^{3-5}$. It was therefore unexpected to find a lack of immune-mediated mucosal damage upon acute deletion of intestinal epithelial CD47, yet this observation is consistent with initial studies reporting that $C d 47^{-1-}$ mice are more or less healthy in pathogen-free conditions ${ }^{10}$. Although the reason for healthy $C d 47^{\triangle I E C}$ mice is not clear, certain macrophage functions could be dependent on licensing through exposure to CD47expressing cells during development in order to sense CD47deficient cells as non-self $f^{5}$. We found that both $C d 47^{\Delta I E C}$ and tamoxifen-treated $C d 47^{\text {ER } \triangle I E C}$ mice did not experience spontaneous immune-mediated destruction of the intestinal epithelium. $C d 47^{\text {ER } \triangle I E C}$ mice were more sensitive to DSS-induced colitis than $\triangle$ IEC mice, suggesting the possibility of a minor degree of innate immune compensation may occur during development. However, our observation that acute deletion of CD47 in the intestinal epithelium of adult $C d 47^{\mathrm{ER} \triangle \mathrm{IEC}}$ mice is not sufficient to perturb intestinal homeostasis argues against this concept, as tissueresident macrophages in these mice are continuously exposed to CD47-expressing epithelial cells prior to tamoxifen administration. Overall, our findings support a growing body of evidence suggesting that phagocytic activity directed at CD47-deficient cells likely involves other pro-phagocytic signals, or may be restricted to specific populations of macrophages and dendritic cells in vivo.

The process of mucosal barrier restitution upon wounding is dependent on coordinated migration of wound-adjacent epithelial cells ${ }^{15}$, whereas epithelial cell adhesion and migration is known to be dependent on the dynamic regulation of $\beta 1$ integrincontaining focal adhesions ${ }^{17,18}$. Experiments conducted in vitro with 2D cultures of primary epithelial cells derived from murine enteroids or human colonoids confirmed that the absence or blockade of CD47 is sufficient to impair migratory capacity of 
wounded epithelial monolayers. The current studies provide mechanistic evidence that epithelial CD47 expression regulates mucosal wound closure in vivo by promoting signaling through a $\beta 1$ integrin-dependent FAK-Src-p130Cas pathway ${ }^{39,41,50}$, thereby enabling focal adhesion complex formation and epithelial cell migration across wounded surfaces. Given that CD47 is expressed ubiquitously, these data suggest that CD47 may function as a fundamental regulator of integrin-dependent cellular processes in many tissues. In support of this, cellular processes as distinct as neuronal development ${ }^{51}$, smooth muscle cell chemotaxis ${ }^{21}$, and leukocyte adhesion and phagocytosis ${ }^{23,37,38,52}$ are reported to require both CD47 expression and the dynamic regulation of integrins. The exact nature of the interaction between CD47, $\beta 1$ integrins and focal adhesions remains to be elucidated. In situ proximity ligation assays (PLA) confirmed close interaction between CD47 and integrin $\beta 1$, as positive PLA signals were detected both in IEC and immune cells. These findings are consistent with other studies reporting direct interactions between CD47 and $\beta 1$ integrins, $\alpha 2 \beta 1$ and $\alpha 4 \beta 1^{53,54}$.

We detected reduced expression of $\beta 1$ integrin protein and reduced/altered focal adhesions in CD47-deficient epithelial cells, suggesting that CD47 may facilitate cell migration by stabilizing $\beta 1$ integrin protein expression. This would, in turn, promote the formation of, or prevent the dissolution of, $\beta 1$ integrin-containing focal adhesion complexes ${ }^{40,55,56}$. Furthermore, we observed that in the absence of CD47 on IEC, phosphorylation of $\mathrm{Src}^{\mathrm{Y} 416}$ was reduced under basal conditions in freshly isolated IEC from $C d 47^{\Delta \mathrm{IEC}}$ mice as well as in $2 \mathrm{D}$ primary IEC cultures in response to wound scratch injury. Our results in IEC corroborate previous studies in CD47-deficient neurons, demonstrating that autophosphorylation of Src was reduced, whereas overexpression of CD47 resulted in Src autophosphorylation ${ }^{51}$. Noteworthy, inhibition of Src has been reported to prevent CD47-promoted neuronal dendrite development as well as CD47-induced epithelial cell spreading, supporting a role for CD47 in epithelial cell migration and dendrite development via regulation of Src activity ${ }^{51,57}$.

The mechanism by which CD47 activates Src kinase is currently unknown. Given our findings of reduced phosphorylation of FAK in the absence of CD47 on IEC and reports of FAK acting as a molecular scaffold protein that recruits and activates Src, we speculate that FAK may play a key role in the regulation of Src by CD47. Of note, it has also been reported that Src-induced tyrosine phosphorylation of FAK is required for focal adhesion activity ${ }^{50,58}$. Collectively, these observations provide evidence for involvement of a functional axis consisting of CD47-FAK-Src in regulating $\mathrm{CD} 47$-dependent IEC migration. Interestingly, we found that the widely used anti-CD47 antibody $\mathrm{B} 6 \mathrm{H} 12$, that inhibits binding of both ligands SIRP- $\alpha$ and TSP-1 to CD47, also resulted in reduced wound healing when applied to human stem cell-derived colonoids in vitro. Given that these human colonoids do not express SIRP- $\alpha$ (Supplementary Fig. 8), our results suggest that the effect of $\mathrm{B} 6 \mathrm{H} 12 \mathrm{mAb}$ on epithelial wound healing may be owing in a large part to inhibition of the interactions between CD47 and TSP-1. However, we cannot exclude the possibility that binding of $\mathrm{B} 6 \mathrm{H} 12 \mathrm{mAb}$ on $\mathrm{CD} 47$ may trigger intracellular signaling, as has been described in other types of cells (Supplementary Fig. 9) $)^{59,60}$.

Previous studies have reported that Tsp1-deficient mice displayed delayed wound healing and increased susceptibility to colitis $^{30,61}$. Furthermore, TSP-1 is a major physiologic activator of latent TGF- $\beta 1$, and TGF- $\beta 1$ is described to be important for collagen deposition facilitating wound healing ${ }^{29,32}$. Here, we found that loss of CD47 on IEC resulted in reduced expression of TSP-1, cleaved/ active form of TGF- $\beta 1$ as well as reduced phosphorylation of TGF- $\beta 1$ downstream effectors, Smad2, and Smad3 in freshly isolated IEC from $C d 47^{\Delta \mathrm{IEC}}$ mice. We also observed less collagen staining in $C d 47^{\Delta \mathrm{IEC}}$ mice compared with $C d 47^{\mathrm{f} / \mathrm{f}}$ mice three days after biopsy and following chronic DSS. It is tempting to speculate that decreased levels of expression of TSP-1 might contribute to observed phenotype in CD47-deficient IEC. These findings appear to be at odds with a report of improved wound repair in a dermal injury model using Cd47-deficient mice showing increased expression of TSP-1, activation of TGF- $\beta 1$, increased $S m a d 2 / 3$ phosphorylation and increased deposition of collagen $^{29}$; however, the latter used animals lacking CD47 in all cells of the body in contrast to our study that used mice with selective depletion of CD47 in IEC. Despite this difference, it is entirely possible that CD47 function in dermal epithelium is different than in IEC. Furthermore, both of these studies clearly support important contributions of CD47, TSP- 1 , and TGF- $\beta 1$ in regulating epithelial repair after injury while highlighting the existence of tissue-specificity in the contributions of CD47 wound healing.

Although the precise mechanism by which CD47, TSP-1, and TGF- $\beta 1$ cooperate to promote intestinal wound healing is unclear, it is possible that reduced levels of TSP-1 may lead to less activation of TGF- $\beta 1$. This hypothesis is consistent with a previous report of Tsp1-deficient mice that exhibited aberrant skin wound healing, and topical application of a TSP-1-derived peptide (KRFK) was shown to enhance local expression of TGF- $\beta 1$ in the wounds of Tsp1-deficient mice and rescued the wound healing process ${ }^{32}$. Moreover, TSP-1 and TGF- $\beta 1$ have been reported to regulate FAK activity ${ }^{62}$ and ligation of CD47 by TSP1 or specific TSP-1 peptides has been shown to regulate av $\beta 3$ integrin-mediated cell spreading ${ }^{63}$. It is likely that TSP-1 and TGF- $\beta 1$ might also functionally link CD47 to FAK. Collectively, these findings suggest the existence of a complex molecular network that regulates the CD47-dependent activation of FAK as well as IEC migration. Indeed, other CD47-associated proteins may also contribute to the process such as ubiquitin-related protein, PLIC-1 which has been suggested to regulate the actin cytoskeleton and cell migration ${ }^{64,65}$. The individual contributions of these signaling networks in regulating IEC migration after injury require further investigation.

Moreover, our observation that blockade of CD47 by antibody administration is sufficient to impair mucosal wound healing raises important considerations for therapeutic targeting of CD47. As immunotherapeutics directed against tumorexpressed CD47 are currently being tested in clinical trials, impaired wound healing may be an unintended consequence in cancer patients undergoing surgical resection, particularly in the gastrointestinal tract.

\section{Materials and methods}

Mice. $C d 47$ knockout mice on a $\mathrm{C} 57 \mathrm{Bl} / 6$ background were purchased from Jackson Laboratories and bred in-house at the University of Michigan in Ann Arbor. Cd47 $\mathrm{f} / \mathrm{f}$ mice were generated on a $\mathrm{C} 57 \mathrm{Bl} / 6$ background from Cd47mla(KOMP)Mbp knockout first ES cells obtained from the Knockout Mouse Repository at UC Davis (I.D. CSD44832) at the Mouse Transgenic and Gene Targeting Core at Emory University in Atlanta, GA. Villin Cre; Cd47 f/f $\left(C d 47^{\Delta \mathrm{IEC}}\right)$, Villin ${ }^{\mathrm{ERT} 2-\mathrm{Cre}}$; $d 47^{\mathrm{f} / \mathrm{f}}$ $\left(C d 47^{\mathrm{ER} \Delta \mathrm{IEC}}\right)$ and respective control littermates $C d 47^{\mathrm{f} / \mathrm{f}}$ mice were bred in-house at the University of Michigan in Ann Arbor. Eight-week-old Cd47 $7^{\text {ER } \Delta I E C}$ and control $C d 47^{\mathrm{f} / \mathrm{f}}$ were injected intraperitoneally (i.p.) with $1 \mathrm{mg} / 100 \mu \mathrm{l}$ of tamoxifen (T5648, Sigma) dissolved in sterile Corn oil (C8267, Sigma) for 5 consecutive days. Animals were used on days 15 after the last tamoxifen injection. For antibody neutralization experiments, 8-week-old male $\mathrm{C} 57 \mathrm{Bl} / 6 \mathrm{~J}$ mice were purchased from Jackson Laboratories. Mice were housed under specific pathogen-free conditions and used at 8-12 weeks of age. All experiments were approved and conducted in accordance with guidelines set by the University of Michigan Institutional Animal Care and Use Committee.

Dextran sulfate sodium treatment. Mice were provided with $2.5 \% \mathrm{w} / \mathrm{v}$ DSS (40$\mathrm{kDa}, 14489$, Affymetrix) in drinking water ad libitum for indicated times followed by 5 days with normal drinking water ${ }^{48,49}$. Clinical disease assessment was obtained daily, with scores of $0-4$ assigned for weight loss, stool consistency, and 
presence of blood in stools. The individual scores were added and the average recorded as the disease activity index (DAI). Higher values of DAI reflect increasing severity of colitis. At the end of the experiment, mice were sacrificed and colons harvested. Hematoxylin-Eosin (H\&E) staining of sections of Swiss roll mounts of the entire colon ( $8-\mu \mathrm{m}$ thick) was performed to quantify colonic mucosal injury. Percentage of injury/ulceration was calculated as a ratio of the length of injured/ulcerated area ( $\geq 50 \%$ crypt loss) relative to the entire colon length.

Reagents. Function-blocking anti-CD47 antibody (clone B6H12.2) was purified from supernatants of hybridoma cells obtained from the American Tissue Culture Collection (ATCC ${ }^{52}$. Antibodies against human SIRPaD1 (clones SAF10.1 and SAF17.2) or SIRPaD3 (SAF4.2) were produced in our laboratory ${ }^{70}$.

The following antibodies were purchased for Western Blot (WB), Immunohistochemistry (IF/IHC), Flow cytometry (FC) or neutralization assays: From AbCam: anti-integrin beta 1 (clone KMI6; ab95623; WB:1/1000), anti-Ki67 (ab15580; IF:1/250), Anti-thrombosponsdin-1 (ab85762; WB:1/500). From BD Pharmingen: anti-human b1 integrin (clone HUTS-21; Cat.556048 at $10 \mu \mathrm{g} / \mathrm{ml}$ ), PerCP Anti-Mouse CD45 (clone 30-F11; Cat.557235; FC:1/200), PE-Cy7 AntiMouse CD3e (clone 145-2C11; Cat.552774; FC:1/200). BV421 Anti-Mouse Siglec F (clone E50-2440; Cat.562681; FC:1/200), BV510 Anti-Mouse CD4 (clone RM4-5; Cat.563106; FC:1/200). From Biolegend: Anti-mouse Ly6G (clone 1A8; Cat.127602; IHC:1/50). PE/Cy7 anti-mouse Ly6C (clone HK1.4; Cat.128018; FC:1/200), PerCP anti-mouse Ly6G (clone 1A8; Cat.127654; FC:1/200). From BioXCell: Purified rat IgG2A (clone 2A3; BP0089), miap301 (BE0270), and miap410 (BE0283) at $10 \mu \mathrm{g} / \mathrm{ml}$. From Cell Signaling Technology: Anti-phospho-FAK (Tyr397; Cat.3283; WB:1/ 1000), Anti-FAK (Cat.3285; WB:1/1000), anti-phospho-p130CAS (Tyr410; Cat.4011; WB:1/1000), Anti-p130CAS (E1L9H; Cat.13846; WB:1/1000), phosphoSrc (Tyr416) (clone D49G4; Cat.6943; WB:1/1000), Anti-Src (Clone 32G6; Cat.2123; WB:1/1000), phospho-SMAD2 (Ser465/Ser467 clone E8F3R; Cat.18338; WB:1/250), phospho-Smad3 (Ser423/425 Clone C25A9; Cat.9520; WB:1/500), Anti-Smad2/3 (Cat.5678; WB:1/1000). From GeneTex: Anti-Villin (GTX109940; IF:1/500). From Invitrogen: Alexa Fluor Secondary Antibodies for immunofluorescence (d:1/500), PE-Cyanine7 Anti-mouse F4/80 (clone BM8; Cat.25-4801-82; FC:1/200), PE Anti-mouse CD19 (clone 1D3; Cat.12-0193-83; FC:1/200), PE Anti-mouse CD11b (clone M1/70; Cat.RM2804; FC:1/200), APC Anti-mouse CD11c (clone N418; Cat.17-0114-82; FC:1/200), PE Anti-CD11b (clone M1/70; Cat.12-0112-83; FC:1/200), FITC Anti-CD8a (clone 53-6.7; Cat.110081-85; FC:1/200). From Millipore: Anti-phospho-FAK (Tyr 861; Cat.07-832; WB:1/1000). From Novus Biologicals: Anti-TGF-b1 (clone 7F6; NBP2-22114; d:1/ 250). From R\&D systems: Anti-mouse CD47 (AF1866; WB:1/2000, IF:1/100), Anti-mouse E-Cadherin (AF748; IF:1/100), Rat anti- mouse Integrin beta 1 (MAB2405; IF:1/100). From Sigma Aldrich: Anti-beta actin (clone AC-15; A5441; WB:1/5000), Anti-GAPDH (G9545; WB:1/5000). From Thermofisher Scientific: Zenon-Alexa Fluor 488 Mouse IgG2a Labeling Kit (Z25102), Alexa Fluor 488conjugated goat-anti-mouse (A11029; IF/FC:1/500), Anti-phospho-FAK (Tyr397; Cat.44-624 G; IF:1/100), Anti-phospho-FAK (Tyr 861; Cat.44-626 G; IF_d:1/100). Anti-mouse CD47 (clone 2D3; Cat.14-0478-82;10 $\mu \mathrm{g} / \mathrm{ml})$. Secondary antibodies for Western blot analysis were obtained from Jackson ImmunoResearch Laboratories.

\section{Intestinal enteroid and monolayer culture. Murine small intestinal epithelial} enteroids/colonoids were created and maintained in culture. Mouse intestine was dissected and flushed with phosphate-buffered saline (PBS) and transferred to chelation buffer ( $2 \mathrm{~mm}$ EDTA, PBS) for $30 \mathrm{~min}$. The intestine was shaken to remove crypt cells and then incubated in PBS with $43 \mathrm{~mm}$ sucrose and $55 \mathrm{~mm}$ sorbitol and filtered through a $70-\mu \mathrm{m}$ filter ${ }^{67}$. Isolated intestinal crypts from untreated $C d 47^{\mathrm{ER} \Delta \mathrm{IEC}}$ mice were embedded in Matrigel (BD Biosciences) $(30 \mu \mathrm{l} /$ well) and maintained in LWRN conditioned complete media supplemented with $50 \mathrm{ng} / \mathrm{ml}$ recombinant human EGF (R\&D Systems) and 100× antibiotics-antimycotic (Corning). In some experiments, enteroid cultures derived from $C d 47^{\mathrm{ER} \Delta \mathrm{IEC}}$ mice, were treated for $72 \mathrm{~h}$ with $1 \mu \mathrm{m} \mathrm{z}$-4-hydroxytamoxifen (\#H7904, Sigma Aldrich) in complete media to acutely knockdowm CD47 followed by passage and maintenance in tamoxifen-free complete media.

LGR5+ stem cell-derived human colonoids were provided by Jason Spence (University of Michigan) and maintained in Matrigel (BD Biosciences) in GMGF media composed of Advanced DMEM/F12, 10\% FBS, 2 mM GlutaMAX-1, $10 \mathrm{~mm}$ HEPES, and $100 \mathrm{U} / \mathrm{ml}$ Penicillin/streptomycin (all from Invitrogen) ${ }^{68}$.

To generate $2 \mathrm{D}$ epithelial intestinal monolayers from murine or human $3 \mathrm{D}$ enteroids/colonoids, a single-cell suspension was obtained by resuspension in $0.05 \%$ Trypsin/0.5 mM EDTA and vigorously pipetting up and down. Trypsin was inactivated by adding $1 \mathrm{ml}$ advanced DMEM/F12- containing 10\% FBS. Dissociated cells were passed through a $40 \mu \mathrm{m}$ cell strainer, then cultured in collagen type IV-coated 48-well tissue culture plates until confluency was achieved $(\sim 48 \mathrm{~h})$. Murine $2 \mathrm{D}$ cultures were maintained in LWRN complete media supplemented with $50 \mathrm{ng} / \mathrm{ml}$ recombinant human EGF and antibiotics/ antimycotic. Human 2D cultures were maintained in differentiation media containing GMGF media supplemented with $10 \mathrm{~nm}$ Gastrin and $1 \mathrm{~mm} N$ Acetylcysteine (Sigma), $10 \mathrm{~mm}$ Nicotinamide, $10 \mu \mathrm{M}$ SB202190 (StemCell Tech), 500 nm A83-01 (StemCell Tech), 10 ng/ml EGF (R\&D systems) ${ }^{68}$.
Wound healing assays. For in vitro experiments, 2D cultures of murine or human epithelial enteroids/colonoids were subjected to scratch wounding assays. Monolayers were cultured on collagen type IV (\#C5533, Sigma)-coated 48-well tissue culture plates to confluency and scratched using a $10 \mu$ l pipette tip under suction. Medium was changed after wounding and video quantification of scratch-wound closure was performed by imaging wounds at $10 \mathrm{~min}$ intervals in an Axiovert Observer live cell microscopy system (Zeiss). Wound closure was quantified at the indicated time points using ImageJ software (National Institutes of Health), calculated as percent reduction of cell-free surface area compared with immediately after wounding $(t=0)^{66}$. For antibody-mediated neutralization experiments, antibodies were added immediately after wounding (time 0 ). Human primary epithelial monolayers were treated for $24 \mathrm{~h}$ with $10 \mu \mathrm{g} / \mathrm{ml}$ of IgG control (14-471482; Thermofisher), function-blocking anti-CD47 antibody (clone B6H12.2) or nonblocking anti-CD47 antibody (clone 2D3). Mouse primary epithelial monolayers were treated for $24 \mathrm{~h}$ with $10 \mu \mathrm{g} / \mathrm{ml}$ of rat IgG2A (clone 2A3), miap301 or miap410. For Western Blot analysis, multiple scratches were created to enrich the migratory fraction of cells before being collected in lysis buffer at indicated times.

For in vivo wounding experiments, a biopsy-based mucosal wound model was employed employed using a high-resolution video endoscope (Coloview Veterinary Endoscope, Karl Storz) equipped with biopsy forceps to create biopsy-induced injury of the colonic mucosa at five to seven sites along the dorsal aspect of the colon of anesthetized mice (i.p. injection of ketamine $100 \mathrm{mg} / \mathrm{kg}$, xylazine $5 \mathrm{mg} / \mathrm{kg}$ ). Wound healing was quantified at $24 \mathrm{~h}$ and $72 \mathrm{~h}$ after injury. Endoscopic procedures were viewed with high-resolution $(1024 \times 768$ pixels $)$ images on a flat-panel color monitor. Each wound region was digitally photographed at $24 \mathrm{~h}$ and $72 \mathrm{~h}$, and wound areas calculated using ImageJ (National Institute of Health, USA). In each experiment, three to five wounds per mouse were quantified ${ }^{66}$. For antibodymediated neutralization experiments, rat IgG2A (clone $2 \mathrm{~A} 3$ ), miap301 or miap410 antibodies were intraperitoneally-administrated ( $400 \mu \mathrm{g}$ in sterile PBS) or were injected directly into wound beds via veterinary endoscope $24 \mathrm{~h}$ post-wounding (10 $\mu \mathrm{g}$ in sterile PBS).

For immunofluorescence analysis, wounds were harvested from colons by punch biopsy, embedded and flash-frozen in OCT embedding compound, followed by sectioning $(6 \mu \mathrm{m}$ thick) and staining as indicated.

Immunofluorescence. Frozen tissue sections ( $6 \mu \mathrm{m}$ thick) were fixed at room temperature in $4 \%$ paraformaldehyde, followed by blocking and permeabilization with $3 \%$ bovine serum albumin/0.5\% Triton X-100 in PBS. Primary antibodies were incubated overnight at $4^{\circ} \mathrm{C}$ in blocking buffer, followed by fluorescent secondary antibodies at room temperature for $1 \mathrm{~h}$. Alexa Fluor 555 Phalloidin (A34055, Invitrogen) was used to stain F-actin and DAPI (4',6-Diamidino-2Phenylindole, Dihydrochloride) (D1306, Invitrogen) for nuclei. Slides were washed and mounted with Pro-Long Antifade Reagent (Thermo Fisher) prior to analysis as indicated.

In situ proximity ligation assay (PLA) was used to identify interactions between CD47 and integrin $\beta 1$. Positive PLA signals, detected as a fluorescent dot by immunofluorescence microscopy, are produced when two labeled proteins are closely apposed within $40 \mathrm{~nm}$. In situ PLA was performed on frozen tissue sections, fixed at room temperature in $4 \%$ paraformaldehyde, followed by blocking and permeabilization with $3 \%$ bovine serum albumin/0.5\% Triton X-100 in PBS. DuoLink PLA probes and reagents (Sigma Aldrich) were used following the manufacturer's instructions. Anti-Goat plus/DUO92003 was used to label antiCD47 antibody and probemaker minus/DUO92010 for anti-integrin $\beta 1$ antibody. Tissues were then stained with anti-beta-catenin antibody and DAPI. Positive and negative control experiments were performed using colonic mucosa from $C d 47^{+/+}$ and $C d 47^{-I-}$ mice, respectively.

Western blot. Cells were lysed in RIPA buffer ( $150 \mathrm{~mm} \mathrm{NaCl}, 1 \%$ NP- $40,0.5 \%$ deoxycholic acid, $0.1 \%$ SDS, $50 \mathrm{~mm}$ Tris $\mathrm{pH}$ 8.0), followed by sonication and centrifugation. Protein concentrations were quantified using BioRad DC Protein Assay (BioRad). Equal quantities of protein samples were loaded into $8 \%$ polyacrylamide gels for SDS-PAGE and transferred to polyvinylidene fluoride membrane. Membranes were blocked with either 5\% dry milk/TBS/Tween-20 or 3\% BSA/TBS/Tween-20 for phosphorylated proteins, followed by overnight incubation with primary antibodies at $4{ }^{\circ} \mathrm{C}$. Membranes were then incubated with appropriate HRP-conjugated secondary antibodies for $1 \mathrm{~h}$ at room temperature, followed by development using Clarity Western ECL Substrate and image capture by ChemiDoc imager (BioRad). Uncropped and unprocessed scans of western blots are provided in the source data file.

Flow cytometry. Lamina propria digests were prepared from whole colonic tissue by washing with chelation buffer to remove epithelial cells (10 mM EDTA in PBS), followed by digestion in RPMI media with $200 \mu \mathrm{g} / \mathrm{ml}$ Liberase TM (Roche Applied Science, Indianapolis, IN) and $200 \mathrm{U} / \mathrm{ml}$ DNase I (Sigma Aldrich). Cells were suspended in flow buffer (2\% FBS/1 mm EDTA in DPBS) and incubated with the following fluorescent conjugated anti-mouse antibodies for $30 \mathrm{~min}$ at $4{ }^{\circ} \mathrm{C}$ : $\mathrm{CD} 45$, F4/80, CD11b, CD11c, Ly6G, Ly6C, Siglec F, CD19, CD3e, CD4, and CD8a.

For detection of SIRPa, human epithelial colonoids were harvested by trypsinization, and washed twice in PBS. As positive controls, human peripheral 
blood polymorphonuclear leukocytes were isolated from whole blood obtained from healthy human volunteers, with approval from University of Michigan institutional review boards on human subjects. Human peripheral venous blood was collected and neutrophils were isolated using density gradient centrifugation on Polymorphprep (Cosmo Bio Usa Inc AXS1114683) at $450 \times g$ for $35 \mathrm{~min}$ at $20{ }^{\circ} \mathrm{C}$. Contaminating erythrocytes were removed by hypotonic lysis. Neutrophils isolated with this method were $97 \%$ pure and $>95 \%$ viable ${ }^{69}$. Cells were then suspended in $200 \mu \mathrm{l}$ of PBS containing $2 \%$ FBS and incubated with $10 \mu \mathrm{g} / \mathrm{ml}$ of murine monoclonal antibodies against human SIRPaD1 (clones SAF10.1 and SAF17.2) or SIRPaD3 (SAF4.2) 70 or anti-human CD47 (clone B6H12) mAb for $45 \mathrm{~min}$ at $4{ }^{\circ} \mathrm{C}$. After incubation, cells were washed twice in PBS containing $2 \%$ FBS, and incubated for $30 \mathrm{~min}$ at $4{ }^{\circ} \mathrm{C}$ with an Alexa Fluor 488-conjugated goatanti-mouse $\mathrm{Ab}$.

To evaluate integrin $\beta 1$ activation after antibody binding to CD47, human epithelial colonoids were harvested by trypsinization, and washed twice in HEPES/ $\mathrm{NaCl}$ buffer (20 mm HEPES, $150 \mathrm{~mm} \mathrm{NaCl}, 2 \mathrm{mg} / \mathrm{ml}$ D-glucose, $\mathrm{pH}$ 7.4). $\beta 1$ integrin activation was detected by using anti- $\beta 1$ integrin epitope antibody HUTS-21 previously labeled with Zenon-Alexa Fluor 488 Mouse IgG2a Labeling Kit (Cat\# Z25102, Invitrogen), following manufacturer instructions. Cells were incubated either with $20 \mu \mathrm{g} / \mathrm{ml}$ of $\mathrm{B} 6 \mathrm{H} 12 \mathrm{mAb}$ or after addition of $1 \mathrm{~mm} \mathrm{Mn}{ }^{2+}$, as a positive to induce integrin activation, in presence of anti- $\beta 1$ integrin epitope Ab HUTS-21 to detect activation of $\beta 1$ integrin. After $30 \mathrm{~min}\left(37^{\circ} \mathrm{C}\right)$, cells were fixed in $4 \%$ paraformaldehyde for $10 \mathrm{~min}$ at room temperature followed by analysis on a NovoCyte flow cytometer (ACEA Biosystems, San Diego, CA). Data files were analyzed using FlowJo software (Tree Star, Ashland, OR)

Statistics. Statistical significance was measured by Student's $t$ test, one-way or twoway ANOVA using Graphpad Prism software. Significance was set as $p \leq 0.05$. Results are expressed as means \pm standard error of mean.

Reporting summary. Further information on research design is available in the Nature Research Reporting Summary linked to this article.

\section{Data availability}

The authors declare that all data supporting the findings of this study are available within the paper and its supplementary information files, or from the corresponding author on reasonable request.

Received: 2 July 2018; Accepted: 7 October 2019;

Published online: 01 November 2019

\section{References}

1. Blazar, B. R. et al. CD47 (integrin-associated protein) engagement of dendritic cell and macrophage counterreceptors is required to prevent the clearance of donor lymphohematopoietic cells. J. Exp. Med. 194, 541-549 (2001).

2. Ishikawa-Sekigami, T. et al. SHPS-1 promotes the survival of circulating erythrocytes through inhibition of phagocytosis by splenic macrophages. Blood 107, 341-348 (2006).

3. Oldenborg, P. A., Gresham, H. D. \& Lindberg, F. P. CD47-signal regulatory protein alpha (SIRPalpha) regulates Fcgamma and complement receptormediated phagocytosis. J. Exp. Med. 193, 855-862 (2001).

4. Oldenborg, P. A. et al. Role of CD47 as a marker of self on red blood cells. Science 288, 2051-2054 (2000).

5. Wang, H. et al. Lack of CD47 on nonhematopoietic cells induces split macrophage tolerance to CD47null cells. Proc. Natl. Acad. Sci. USA 104, 13744-13749 (2007).

6. Yi, T. et al. Splenic dendritic cells survey red blood cells for missing selfCD47 to trigger adaptive immune responses. Immunity 43, 764-775 (2015).

7. Huang, Y., Ma, Y., Gao, P. \& Yao, Z. Targeting CD47: the achievements and concerns of current studies on cancer immunotherapy. J. Thorac. Dis. 9, E168-E174 (2017).

8. Liu, X., Kwon, H., Li, Z. \& Fu, Y. X. Is CD47 an innate immune checkpoint for tumor evasion? J. Hematol. Oncol. 10, 12 (2017).

9. Lamy, L. et al. Interactions between CD47 and thrombospondin reduce inflammation. J. Immunol. 178, 5930-5939 (2007).

10. Lindberg, F. P. et al. Decreased resistance to bacterial infection and granulocyte defects in IAP-deficient mice. Science 274, 795-798 (1996).

11. Navarathna, D. H. et al. CD47 promotes protective innate and adaptive immunity in a mouse model of disseminated candidiasis. PLOS ONE 10, e0128220 (2015).

12. Parkos, C. A. et al. CD47 mediates post-adhesive events required for neutrophil migration across polarized intestinal epithelia. J. Cell Biol. 132, 437-450 (1996).
13. Soto-Pantoja, D. R., Ridnour, L. A., Wink, D. A. \& Roberts, D. D. Blockade of CD47 increases survival of mice exposed to lethal total body irradiation. Sci. Rep. 3, 1038 (2013).

14. Su, X., Johansen, M., Looney, M. R., Brown, E. J. \& Matthay, M. A. CD47 deficiency protects mice from lipopolysaccharide-induced acute lung injury and Escherichia coli pneumonia. J. Immunol. 180, 6947-6953 (2008).

15. Leoni, G., Neumann, P. A., Sumagin, R., Denning, T. L. \& Nusrat, A. Wound repair: role of immune-epithelial interactions. Mucosal Immunol. 8, 959-968 (2015).

16. Choma, D. P., Pumiglia, K. \& DiPersio, C. M. Integrin alpha3betal directs the stabilization of a polarized lamellipodium in epithelial cells through activation of Rac1. J. Cell Sci. 117, 3947-3959 (2004).

17. Lotz, M. M. et al. Intestinal epithelial restitution. Involvement of specific laminin isoforms and integrin laminin receptors in wound closure of a transformed model epithelium. Am. J. Pathol. 150, 747-760 (1997).

18. Yamaguchi, N., Mizutani, T., Kawabata, K. \& Haga, H. Leader cells regulate collective cell migration via Rac activation in the downstream signaling of integrin betal and PI3K. Sci. Rep. 5, 7656 (2015).

19. Broom, O. J., Zhang, Y., Oldenborg, P. A., Massoumi, R. \& Sjolander, A. CD47 regulates collagen I-induced cyclooxygenase-2 expression and intestinal epithelial cell migration. PLoS ONE 4, e6371 (2009).

20. Chung, J., Wang, X. Q., Lindberg, F. P. \& Frazier, W. A. Thrombospondin-1 acts via IAP/CD47 to synergize with collagen in alpha2beta1-mediated platelet activation. Blood 94, 642-648 (1999).

21. Wang, X. Q. \& Frazier, W. A. The thrombospondin receptor CD47 (IAP) modulates and associates with alpha2 beta1 integrin in vascular smooth muscle cells. Mol. Biol. Cell 9, 865-874 (1998)

22. Yoshida, $\mathrm{H}$. et al. Integrin-associated protein/CD47 regulates motile activity in human B-cell lines through CDC42. Blood 96, 234-241 (2000).

23. Azcutia, V. et al. CD47 plays a critical role in T-cell recruitment by regulation of LFA-1 and VLA-4 integrin adhesive functions. Mol. Biol. Cell 24, 3358-3368 (2013)

24. Isenberg, J. S. et al. Treatment of liver ischemia-reperfusion injury by limiting thrombospondin-1/CD47 signaling. Surgery 144, 752-761 (2008).

25. Isenberg, J. S. et al. Increasing survival of ischemic tissue by targeting CD47. Circ. Res. 100, 712-720 (2007).

26. Maxhimer, J. B., Shih, H. B., Isenberg, J. S., Miller, T. W. \& Roberts, D. D. Thrombospondin-1/CD47 blockade following ischemia-reperfusion injury is tissue protective. Plast. Reconstr. Surg. 124, 1880-1889 (2009).

27. Rogers, N. M., Thomson, A. W. \& Isenberg, J. S. Activation of parenchymal CD47 promotes renal ischemia-reperfusion injury. J. Am. Soc. Nephrol. 23, 1538-1550 (2012)

28. Soto-Pantoja, D. R., Isenberg, J. S. \& Roberts, D. D. Therapeutic targeting of $\mathrm{CD} 47$ to modulate tissue responses to ischemia and radiation. J. Genet. Syndr. Gene Ther. 2, pii: 1000105 (2011).

29. Soto-Pantoja, D. R. et al. Thrombospondin-1 and CD47 signaling regulate healing of thermal injury in mice. Matrix Biol. 37, 25-34 (2014).

30. Agah, A., Kyriakides, T. R., Lawler, J. \& Bornstein, P. The lack of thrombospondin-1 (TSP1) dictates the course of wound healing in doubleTSP1/TSP2-null mice. Am. J. Pathol. 161, 831-839 (2002).

31. DiPietro, L. A. et al. Thrombospondin 1 synthesis and function in wound repair. Am. J. Pathol. 148, 1851-1860 (1996).

32. Nor, J. E. et al. Activation of latent TGF-betal by thrombospondin-1 is a major component of wound repair. Oral. Biosci. Med. 2, 153-161 (2005).

33. Verdrengh, M., Lindberg, F. P., Ryden, C. \& Tarkowski, A. Integrin-associated protein (IAP)-deficient mice are less susceptible to developing Staphylococcus aureus-induced arthritis. Microbes Infect. 1, 745-751 (1999).

34. Gao, Q. et al. Blockade of CD47 ameliorates autoimmune inflammation in CNS by suppressing IL-1-triggered infiltration of pathogenic Th17 cells. J. Autoimmun. 69, 74-85 (2016).

35. Willingham, S. B. et al. The CD47-signal regulatory protein alpha (SIRPa) interaction is a therapeutic target for human solid tumors. Proc. Natl. Acad. Sci. USA 109, 6662-6667 (2012).

36. el Marjou, F. et al. Tissue-specific and inducible Cre-mediated recombination in the gut epithelium. Genesis 39, 186-193 (2004).

37. Isenberg, J. S. et al. Differential interactions of thrombospondin-1, -2 , and -4 with CD47 and effects on cGMP signaling and ischemic injury responses. $J$. Biol. Chem. 284, 1116-1125 (2009).

38. Lindberg, F. P., Gresham, H. D., Reinhold, M. I. \& Brown, E. J. Integrinassociated protein immunoglobulin domain is necessary for efficient vitronectin bead binding. J. Cell Biol. 134, 1313-1322 (1996).

39. Donato, D. M., Ryzhova, L. M., Meenderink, L. M., Kaverina, I. \& Hanks, S. K. Dynamics and mechanism of p130Cas localization to focal adhesions. J. Biol. Chem. 285, 20769-20779 (2010).

40. Gustavsson, A., Yuan, M. \& Fallman, M. Temporal dissection of beta1integrin signaling indicates a role for p130Cas-Crk in filopodia formation. J. Biol. Chem. 279, 22893-22901 (2004). 
41. Meenderink, L. M. et al. P130Cas Src-binding and substrate domains have distinct roles in sustaining focal adhesion disassembly and promoting cell migration. PLoS ONE 5, e13412 (2010).

42. Punekar, S. et al. Thrombospondin 1 and its mimetic peptide ABT-510 decrease angiogenesis and inflammation in a murine model of inflammatory bowel disease. Pathobiology 75, 9-21 (2008).

43. Crawford, S. E. et al. Thrombospondin-1 is a major activator of TGF-beta1 in vivo. Cell 93, 1159-1170 (1998).

44. Baba, N. et al. CD47 fusion protein targets CD172a+ cells in Crohn's disease and dampens the production of IL-1beta and TNF. J. Exp. Med. 210, 1251-1263 (2013).

45. Demeure, C. E. et al. CD47 engagement inhibits cytokine production and maturation of human dendritic cells. J. Immunol. 164, 2193-2199 (2000).

46. Johansson, U. \& Londei, M. Ligation of CD47 during monocyte differentiation into dendritic cells results in reduced capacity for interleukin-12 production. Scand. J. Immunol. 59, 50-57 (2004).

47. Bian, Z. et al. CD47 deficiency does not impede polymorphonuclear neutrophil transmigration but attenuates granulopoiesis at the postacute stage of colitis. J. Immunol. 190, 411-417 (2013).

48. Oh, S. Y., Cho, K. A., Kang, J. L., Kim, K. H. \& Woo, S. Y. Comparison of experimental mouse models of inflammatory bowel disease. Int J. Mol. Med. 33, 333-340 (2014).

49. Yoshihara, K., Yajima, T., Kubo, C. \& Yoshikai, Y. Role of interleukin 15 in colitis induced by dextran sulphate sodium in mice. Gut 55, 334-341 (2006).

50. Calalb, M. B., Zhang, X., Polte, T. R. \& Hanks, S. K. Focal adhesion kinase tyrosine-861 is a major site of phosphorylation by Src. Biochem. Biophys. Res. Commun. 228, 662-668 (1996).

51. Murata, T. et al. CD47 promotes neuronal development through Src- and FRG/Vav2-mediated activation of Rac and Cdc42. J. Neurosci. 26, 12397-12407 (2006).

52. Liu, Y. et al. The role of CD47 in neutrophil transmigration. Increased rate of migration correlates with increased cell surface expression of CD47. J. Biol. Chem. 276, 40156-40166 (2001).

53. Brittain, J. E., Han, J., Ataga, K. I., Orringer, E. P. \& Parise, L. V. Mechanism of CD47-induced alpha4betal integrin activation and adhesion in sickle reticulocytes. J. Biol. Chem. 279, 42393-42402 (2004).

54. Brown, E. J. \& Frazier, W. A. Integrin-associated protein (CD47) and its ligands. Trends Cell Biol. 11, 130-135 (2001).

55. Partridge, M. A. \& Marcantonio, E. E. Initiation of attachment and generation of mature focal adhesions by integrin-containing filopodia in cell spreading. Mol. Biol. Cell 17, 4237-4248 (2006).

56. Rankin, C. R., et al. Annexin A2 regulates betal integrin internalization and intestinal epithelial cell migration. J. Biol. Chem. 288, 15229-15239 (2013).

57. Shinohara, M. et al. CD47 regulation of epithelial cell spreading and migration, and its signal transduction. Cancer Sci. 97, 889-895 (2006).

58. Guan, J. L. Role of focal adhesion kinase in integrin signaling. Int J. Biochem. Cell Biol. 29, 1085-1096 (1997).

59. Barazi, H. O. et al. Regulation of integrin function by CD47 ligands. Differential effects on alpha vbeta 3 and alpha 4 betal integrin-mediated adhesion. J. Biol. Chem. 277, 42859-42866 (2002).

60. Ticchioni, M. et al. Integrin-associated protein (CD47) is a comitogenic molecule on CD3-activated human T cells. J. Immunol. 158, 677-684 (1997).

61. Gutierrez, L. S. The role of thrombospondin 1 on intestinal inflammation and carcinogenesis. Biomark. Insights 3, 171-178 (2008).

62. Horowitz, J. C. et al. Combinatorial activation of FAK and AKT by transforming growth factor-betal confers an anoikis-resistant phenotype to myofibroblasts. Cell Signal. 19, 761-771 (2007).

63. Gao, A. G., Lindberg, F. P., Dimitry, J. M., Brown, E. J. \& Frazier, W. A. Thrombospondin modulates alpha v beta 3 function through integrinassociated protein. J. Cell Biol. 135, 533-544 (1996).

64. N'Diaye, E. N. \& Brown, E. J. The ubiquitin-related protein PLIC-1 regulates heterotrimeric $\mathrm{G}$ protein function through association with Gbetagamma. J. Cell Biol. 163, 1157-1165 (2003).
65. Wu, A. L., Wang, J., Zheleznyak, A. \& Brown, E. J. Ubiquitin-related proteins regulate interaction of vimentin intermediate filaments with the plasma membrane. Mol. Cell 4, 619-625 (1999).

66. Quiros, M. et al. Macrophage-derived IL-10 mediates mucosal repair by epithelial WISP-1 signaling. J. Clin. Invest. 127, 3510-3520 (2017).

67. Capaldo, C. T. et al. Proinflammatory cytokine-induced tight junction remodeling through dynamic self-assembly of claudins. Mol. Biol. Cell 25, 2710-2719 (2014)

68. Zou, W. Y. et al. Human intestinal enteroids: new models to study gastrointestinal virus infections. Methods Mol. Biol. 1576, 229-247 (2019).

69. Brazil, J. C. et al. Neutrophil migration across intestinal epithelium: evidence for a role of CD44 in regulating detachment of migrating cells from the luminal surface. J. Immunol. 185, 7026-7036 (2010).

70. Lee, W. Y. et al. Novel structural determinants on SIRP alpha that mediate binding to CD47. J. Immunol. 179, 7741-7750 (2007).

\section{Acknowledgements}

We thank the Transgenic and Gene Targeting Core at Emory University, Microscopy and Image Analysis Laboratory and Pathology Flow Cytometry Core facilities at the University of Michigan Medical School. The authors additionally thank the laboratory of Mary Estes at Baylor University for assistance in enteroid culture generation as well as Meenal Mhaskar, Dr. Dorothee Birkl, and Dr. Roland Hilgarth for technical assistance. This work was supported by the following grants: R01-DK079392, R01-DK72564 (C.A.P.), DK055679 (A.N.), T32-HL007517 (M.R.), and support from the Crohns and Colitis Foundation (V.A., M.Q., and J.B.).

\section{Author contributions}

M.R. and A-.C.L. designed, performed experiments, analyzed the data, and wrote the manuscript. V.A., S.F., M.N.O, M.Q. and J.B. assisted with some experiments. A.N. and C.A.P. supervised the study, wrote and edited the manuscript.

\section{Competing interests}

The authors declare no competing interests.

\section{Additional information}

Supplementary information is available for this paper at https://doi.org/10.1038/s41467 019-12968-y.

Correspondence and requests for materials should be addressed to C.A.P.

Peer review information Nature Communications thanks the anonymous reviewers for their contribution to the peer review of this work.

Reprints and permission information is available at http://www.nature.com/reprints

Publisher's note Springer Nature remains neutral with regard to jurisdictional claims in published maps and institutional affiliations.

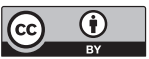

Open Access This article is licensed under a Creative Common Attribution 4.0 International License, which permits use, sharing, adaptation, distribution and reproduction in any medium or format, as long as you give appropriate credit to the original author(s) and the source, provide a link to the Creative Commons license, and indicate if changes were made. The images or other third party material in this article are included in the article's Creative Commons license, unless indicated otherwise in a credit line to the material. If material is not included in the article's Creative Commons license and your intended use is not permitted by statutory regulation or exceeds the permitted use, you will need to obtain permission directly from the copyright holder. To view a copy of this license, visit http://creativecommons.org/ licenses/by/4.0/.

(c) The Author(s) 2019 